\title{
Site Amplification and Attenuation via Downhole Array Seismogram Inversion: A Comparative Study of the 2003 Miyagi-Oki Aftershock Sequence
}

\author{
by Dominic Assimaki, Wei Li, Jamison H. Steidl, and Kenichi Tsuda
}

\begin{abstract}
Weak-motion geotechnical array recordings at 38 stations of the Japanese strong-motion network KiK-Net from the $2003 M_{\mathrm{w}} 7.0$ Miyagi-Oki aftershock sequence are used here to quantify the amplification and attenuation effects of nearsurface formations to incident seismic motion. Initially, a seismic waveform optimization algorithm is implemented for the evaluation of high-resolution, low-strain velocity $\left(V_{s}\right)$, attenuation $\left(Q_{s}\right)$, and density $(\rho)$ profiles at the sites of interest. Based on the inversion results, $V_{s}$ versus $Q_{s}$ correlations are developed, and scattering versus intrinsic attenuation effects are accounted for in their physical interpretation. Surfaceto-downhole traditional spectral ratios (SSR), cross-spectral ratios (c-SSR), and horizontal-to-vertical (H/V) site-response estimates are next evaluated and compared, while their effectiveness is assessed as a function of the site conditions classified on the basis of the weighted average $V_{s}$ of the upper $30 \mathrm{~m}\left(V_{s 30}\right)$ of the formations. Single and reference-station site-response estimates are successively compared to surface-to-rock outcrop amplification spectra and are evaluated by deconvolution of the downhole records based on the inversion results; comparison of the observed SSR and estimated surface-to-rock outcrop amplification spectra illustrates the effects of destructive interference of downgoing waves at the downhole instrument level as a function of the site class. Site amplification factors are successively computed in reference to the National Earthquake Hazards Reduction Program (NEHRP) B-C boundary site conditions ( $V_{s 30}=760 \mathrm{~m} / \mathrm{sec}$ ), and results are compared to published values developed on the basis of strong-motion data and site-response analyses. Finally, weak-motion SSR estimates are compared to the mainshock spectra, and conclusions are drawn for the implications of soil nonlinearity in the near surface. Results presented in this article suggest that currently employed site classification criteria need to be reevaluated to ensure intraclass consistency in the assessment of amplification potentials and nonlinearity susceptibility of near-surficial soil formations.
\end{abstract}

\section{Introduction}

It has been long recognized that the destructiveness of ground shaking during earthquakes can be significantly aggravated by the mechanical properties of surficial geological formations, typically referred to as local soil conditions. Indeed, ground-motion recordings collected in the recent past have revealed in many cases that subsoil characteristics had significant influence on the amplitude level, frequency composition, and duration of surface ground shaking, while the variability in seismic intensity and structural damage severity has been shown to correlate strongly with the variability of soil stratigraphy at a given area. Therefore, realistic ground-motion predictions of future earthquakes can be only achieved by combining source, wave-propagation, and site-response models, and according to Field et al. (1997), an important step toward this goal is the consensus that exists today between the earthquake engineering and seismological community that the response of soft sediments to strong ground motion may significantly affect the catastrophic consequences of large earthquakes.

The increasing number of observations in the last three decades has contributed toward the understanding of strongmotion site effects by the engineering and seismological communities alike and has allowed advancements to be made in the state of knowledge and modeling of sediment response in situ (Field et al., 1997). Nonetheless, further resolution and effective representation of the physics in the near surface 
requires a good estimate of the input motion, and by far the best source of information is provided by downhole arrays. Downhole array recordings obtained in seismically active areas in the recent years (e.g., Japan, Taiwan, California, and Greece) have significantly contributed to the advancement of understanding on the critical mechanisms that govern the seismic response of near-surface geological formations, thus being a valuable complement to existing in situ and laboratory techniques. Among others, borehole measurements provided direct in situ evidence of nonlinearity (e.g., Seed and Idriss, 1970; Wen et al., 1994; Zeghal and Elgamal, 1994; Iai et al., 1995; Sato et al., 1996; Aguirre and Irikura, 1997; Satoh et al., 2001); they have invited a reevaluation of the use of surface-rock recordings as input motion to soil columns (e.g., Satoh et al., 1995; Steidl et al., 1996; Boore and Joyner, 1997), and they have provided basic information about scaling and alluvium sites are located at the surface (e.g., Borcherdt, 1970; Hartzell, 1992; Margheriti et al., 1994; Field and Jacob, 1995; Kato et al., 1995; Field, 1996; Hartzell et al., 1996; Su et al., 1996; Bonilla et al., 1997).

Overall, downhole instrumentation is a valuable complement to in situ and laboratory geotechnical investigation techniques, providing critical constraints both on interpretation methods for surface observations as well as information on the real material behavior and overall site response over a wide range of loading conditions (Assimaki et al., 2006). The amount and quality of information from downhole arrays in seismically active areas is the key to both improve the understanding of in situ soil behavior and to assess the modeling and parametric uncertainty of employed methodologies for strong-motion site-response analysis; this type of validation process that involves full-scale in situ data that only strong-motion arrays can provide is the only one that will be accepted both by engineering practitioners and seismologists and that will result in successful technology transfer of cost-effective and efficient strong-motion site-response analyses (Kramer and Paulsen, 2004).

Toward this target, downhole array seismogram recordings are being used in this study to assess the effectiveness of site-response estimates for weak ground motion and the validity of site-classification criteria and corresponding amplification factors in the description of the amplification potential and nonlinearity susceptibility of near-surface geologic formations. For this purpose a seismic waveform inversion algorithm developed by Assimaki et al (2006) is initially implemented for the evaluation of high-resolution, low-strain shear-wave velocity $\left(V_{s}\right)$, attenuation $\left(Q_{s}\right)$, and density profiles at 37 geotechnical array sites of the Japanese strongmotion network KiK-Net (Aoi et al., 2000); based on the inversion results, $V_{s}-Q_{s}$ correlations are derived for the near-surface $(0-30 \mathrm{~m})$ and underlying $(30-100 \mathrm{~m})$ soil layers and are interpreted to account for the effects of scattering and intrinsic (material) attenuation. Successively, the sites are classified through the weighted average inverted velocity of the upper $30 \mathrm{~m}\left(V_{s 30}\right)$ according to the National Earth- quake Hazards Reduction Program (NEHRP) site classification system.

Weak-motion recordings obtained during the 2003 $M_{\mathrm{w}} 7.0$ Miyagi-Oki aftershock sequence are next used in conjunction with the inverted profiles to evaluate the effectiveness of single-station and reference-station site amplification estimates. In particular, surface-to-downhole traditional (SSR) and cross-spectral (c-SSR) ratios, as well as horizontal-to-vertical (H/V) site-response estimates are compared, and their effectiveness is evaluated as a function of the corresponding site class. The single and reference-station site responses are also compared to surface-to-rock outcrop spectral amplification ratios, evaluated by deconvolution of downhole recorded motions to the rock outcrop of the underlying halfspaces at each site. Comparison between the traditional surface-to-borehole and surface-to-rock outcrop spectral ratios reveals the effects of destructive interference of downgoing waves in the former site-response estimate as function of the soil conditions. Average frequency-dependent site-response estimates in the frequency range $0.5-1,1-3,3-$ $5,5-7$, and 7-10 $\mathrm{Hz}$ are also compared across the methods.

Peak ground acceleration (PGA) and response spectral (SA) site amplification factors for short and long periods (time $T=0.3$ and $1.0 \mathrm{sec}$, correspondingly) are successively computed in reference to the NEHRP B-C boundary site conditions $\left(V_{s 30}=760 \mathrm{~m} / \mathrm{sec}\right)$, and results are compared to standard unified building code provisions and attenuation relation site amplification factors developed on the basis of strong-motion data and site-response analyses. Finally, once the range of effectiveness of weak-motion site-response estimates and site amplification factors is assessed as a function of the soil conditions for the region of interest, surfaceto-borehole weak-motion estimates of site response are compared to the corresponding spectra evaluated for the mainshock of the event, and conclusions are drawn for the implications of soil nonlinearity in the near surface for the site conditions examined.

\section{Stochastic Seismogram Inversion Algorithm with Deterministic Local Hill Climbing}

Nonlinear multiparametric seismogram inversion is typically treated as an optimization problem for which a suitably chosen measure of the data misfit is minimized or maximized as a function of the model parameters. These measures are referred to as objective or fitness functions, and in seismological problems they typically describe either the error energy or the normalized correlation function between recorded data and synthetics. In the forward problem, however, the formulation nonlinearity is reflected on the objective functions as multiple local maxima and minima respectively. Therefore, traditional search techniques based on local linearization, which use characteristics of the problem to determine the next sampling point (e.g., gradients, Hessians, linearity, and continuity), are computationally efficient but fail to identify the best-fit solution when the starting model is too far from 
the global optimal solution. On the other hand, stochastic search techniques (e.g., genetic algorithms and simulated annealing) have been shown to efficiently identify promising regions in the search space, but their convergence rate has been shown to be poor in localized searches (Bersini and Renders, 1994; Houck et al., 1996).

Developed by Assimaki et al. (2006), the optimization technique employed in this article is a two-step process, namely a genetic algorithm in the wavelet domain coupled to a nonlinear least-squares fit in the frequency domain. This approach has been shown to improve the computational efficiency of the former while avoiding the pitfalls of using local linearization techniques such as the latter for the optimization of multimodal, discontinuous, and nondifferentiable functions (Houck et al., 1996). The parameters estimated are stepwise variations of the shear-wave velocity, attenuation, and density with depth for horizontally layered media with predefined layer thickness. Deterministic lower and upper bounds are imposed on the vector of unknowns to constrain the search space based on independent geological and geotechnical site characterization data.

For the global optimization scheme, the objective function is defined as the normalized correlation between observed data and synthetics, as follows (Stoffa and Sen, 1991):

$$
\begin{aligned}
C(m)= & \frac{1}{N_{p}} \sum_{1}^{N_{p}}\left(2 \sum_{1}^{N_{\mathrm{TS}}} a_{0} a_{s}^{*}(m)\right) /\left[\left(\sum_{1}^{N_{\mathrm{TS}}} a_{0} a_{0}^{*}\right)\right. \\
& \left.+\left(\sum_{1}^{N_{\mathrm{TS}}} a_{s}(m) a_{s}^{*}(m)\right)\right],
\end{aligned}
$$

where $a_{0}$ and $a_{s}(m)$ are the observed and synthetic seismograms, respectively, $N_{\mathrm{TS}}$ is the number of time steps, and $N_{p}$ is the number of wavelet decomposition bands of the signal. In this case, the mathematical representation of the forward problem propagates the measured total motion at the borehole depth to the surface through an idealized medium. Successively, the coherency between measured and predicted processes at the surface station of the array maps the similarity between the idealized soil configuration and the real soil structure. Therefore, the objective of the optimization scheme is to maximize the normalized cross correlation, identifying the so-called best-fit layered soil configuration. Decomposing the signal in the wavelet domain and normalizing the approximation and details-as opposed to the original signal-in the objective function definition allow for equal weighting of the information across all frequency bands, an approach preferable to a time-domain representation that would inevitably emphasize the larger amplitude signals of the nonstationary ground motion in time and frequency.

Further accelerating the convergence of the optimization scheme, a local improvement operator is employed at the end of the selection process of each generation. In particular, once the best-fit solutions are identified, a nonlinear Gauss-
Newton scheme is employed, opting at convergence of the active parental generation toward local minima or maxima prior to mutation, crossover, and reproduction. This technique, referred to as the hill-climbing method of local optimization, has been shown to significantly enhance the performance of genetic algorithms (Bersini and Renders, 1994; Houck et al., 1996). The objective function of the nonlinear least-squares optimization is defined in the frequency domain, as the energy error between the model and data vectors:

$$
E(m)=\left(\sum_{1}^{N_{\omega}}\left(A_{0}-A_{s}^{*}[m]\right)^{2}\right) /\left(\sum_{1}^{N_{\omega}} A_{0}^{2}+\sum_{1}^{N_{\omega}}\left(A_{s}^{*}[m]\right)^{2}\right),
$$

where $A_{0}$ and $A_{s}(m)$ are the empirical and theoretical transfer functions, respectively, and $N_{\omega}$ is the number of frequencies.

The algorithm is repeated in series for multiple borehole and surface waveform pairs. Among the total number of available motions recorded at a given station, a subset is selected on the basis of the available signal-to-noise ratio (SNR). The averaging of the optimal solution for multiple events achieves both minimization of the error propagation of the measured process and the effects of the forward numerical model limitations, thus obtaining the most probable best-fit solution to the inverse problem. For further information, the reader is referred to Assimaki et al. (2006) and Assimaki and Steidl (2007).

\section{Seismogram Inversion of the Miyagi-Oki 5 May 2003 Aftershock Sequence}

The 2003 Miyagi-Oki earthquake (26 May 2003, 18:24 UTC, $M_{\mathrm{w}}$ 7.0), an intraslab earthquake of the Pacific plate (Yamanaka and Kikuchi, 2003), occurred at about 70$\mathrm{km}$ depth at an epicentral distance several kilometers offshore, near the boundary of the Miyagi and Iwate refectures $\left(38.806^{\circ} \mathrm{N}, 141.685^{\circ} \mathrm{E}\right.$, National Research Institute for Earth Science and Disaster Prevention [NIED], Hi-Net). The ground motion was widely felt in the northern half of Japan, was recorded at about 800 stations of nationwide strongmotion networks K-Net (Kinoshita, 1998) and KiK-Net (Aoi et al., 2000), and was characterized by very large PGA at many stations (Satoh, 2004).

Despite the large hypocentral distance of most stations (typically on the order of $80 \mathrm{~km}$ or greater), multiple instruments of NIED recorded very large values of PGA; at five stations in particular, including two Japan Meteorological Agency (JMA) stations, PGA exceeded $1 \mathrm{~g}\left(980 \mathrm{~cm} / \mathrm{sec}^{2}\right)$ at an epicental distance of approximately $100 \mathrm{~km}$. Figure 1 illustrates the aftershock distribution as depicted by the Japanese high-sensitivity seismogram network Hi-Net, the ground-motion intensity distribution corresponding to the mainshock event $\left(M_{\mathrm{w}}\right.$ 7.0, 26 May 2003, 18:24 UTC), and the location of $38 \mathrm{KiK}-\mathrm{Net}$ stations used for the purpose of this study. The corresponding station codes, longitude, 


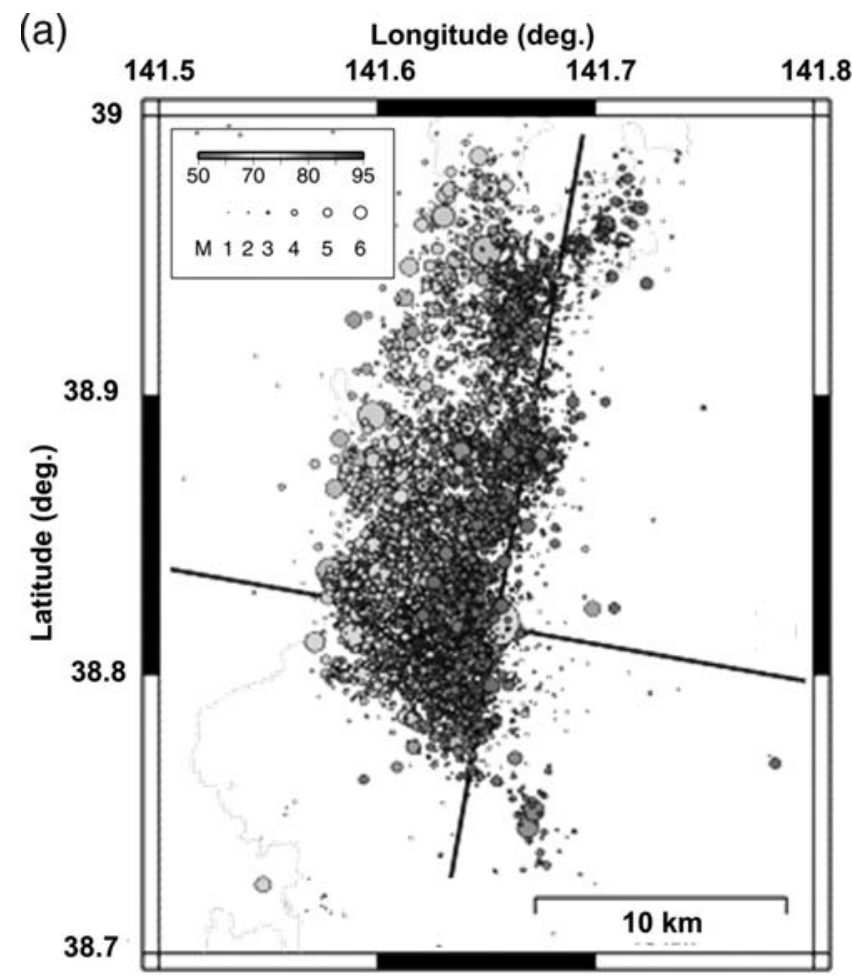

(c)

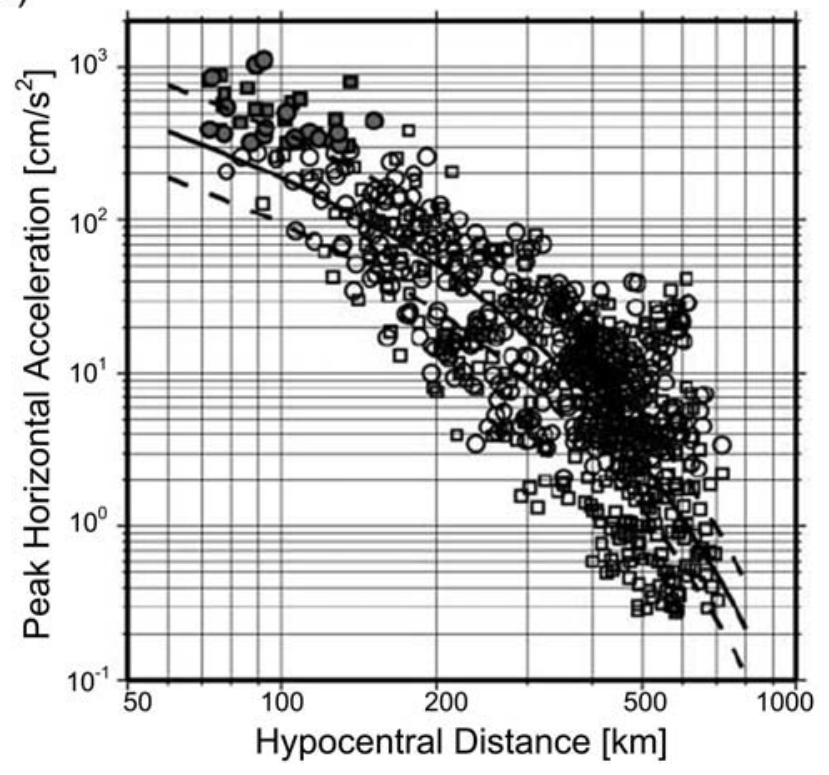

latitude, ground surface elevation, and borehole instrument depths are listed in Table 1.

Finally, the horizontal PGA as a function of hypocentral distance as recorded by K-Net and KiK-Net surface stations is shown in Figure 1c (Tsuda et al., 2006). Also shown is the empirical attenuation curve proposed by Shi and Midorikawa (1999) for the Miyagi and Iwate prefectures, derived by averaging techniques of the observed response during past events. It should be noted that the PGA from this event (b)

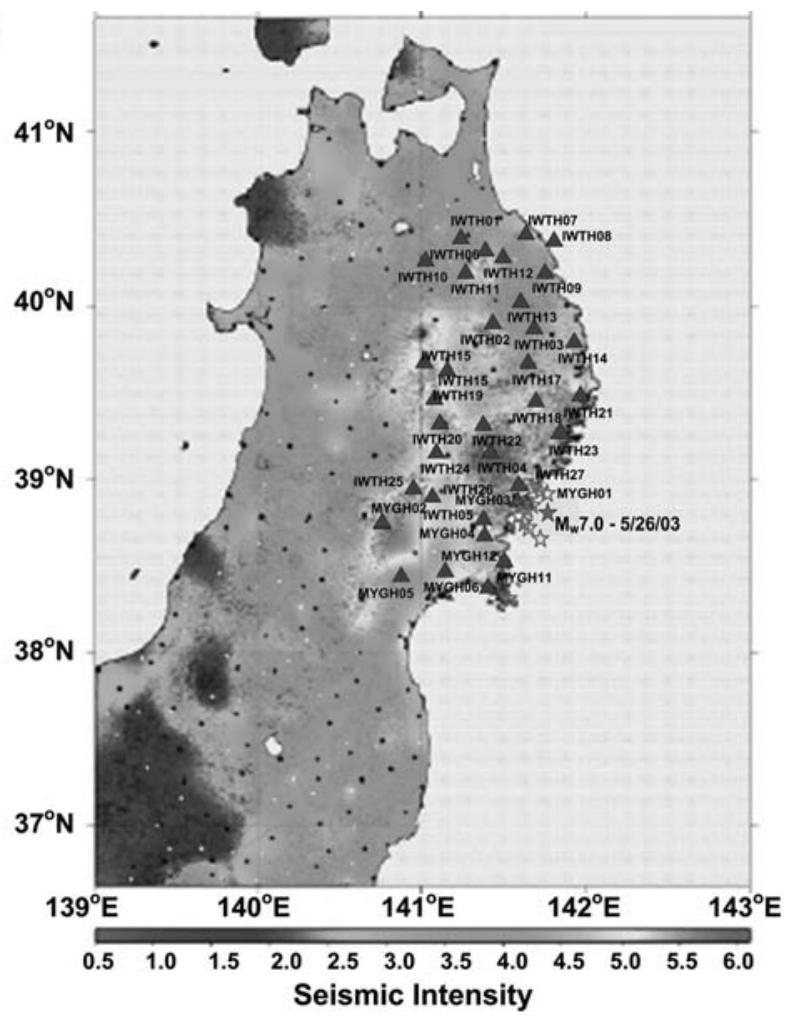

Figure 1. (a) Aftershock distribution by manual picking of Hi-Net data. (b) Ground-motion intensity distribution corresponding to the mainshock event ( $M 7.126$ May 2003 18:24 UTC), and location of the $38 \mathrm{KiK}-\mathrm{Net}$ stations used for the purpose of this study. Depths of the boreholes are larger than $100 \mathrm{~m}$ at most stations, and shear-wave velocities are larger than $500 \mathrm{~m} / \mathrm{sec}$ at the depth of the borehole instruments; the triangles depicted correspond to the station locations used in this study, the solid star to the mainshock epicenter and the open stars to the aftershock epicenters used in this work. (c) Peak horizontal accelerations as a function of hypocentral distance from 26 May 2003 Miyagi-Oki mainshock. The circles and squares correspond to the peak horizontal acceleration by K-Net and KiK-Net, respectively, with gray denoting the stations used in this study. The solid curve shows the empirical attenuation relationship evaluated by Shi and Midorikawa (1999), while the dashed lines correspond to the empirical relation \pm a factor of 2 (Tsuda et al. 2006).

exceeded the empirical relationship described previously, especially for stations at smaller distances, generating large high-frequency ground motions, which are a common characteristic of intraslab earthquakes at close stations (Morikawa and Sasatani, 2003).

Among approximately 240 events recorded at these stations in the period 3 May-14 July 2003, 14 events with $M_{\mathrm{w}}>4$ were selected for the purpose of this study, and the corresponding borehole and surface three-component ac- 
Table 1

KiK-Net Stations Used for the Purpose of This Study

\begin{tabular}{|c|c|c|c|c|c|}
\hline Station Code & Station Name & Latitude (deg) & Longitude (deg) & Surface Altitude (m) & Borehole Depth (m) \\
\hline IWTH01 & NINOHE-E & 40.2356 & 141.3458 & 230 & 200 \\
\hline IWTH02 & TAMAYAMA & 39.8222 & 141.3861 & 675 & 102 \\
\hline IWTH03 & IWAIZUMI & 39.7994 & 141.6556 & 310 & 100 \\
\hline IWTH04 & SUMITA & 39.1781 & 141.3944 & 620 & 106 \\
\hline IWTH05 & FUJISAWA & 38.8625 & 141.3547 & 120 & 100 \\
\hline IWTH06 & NINOHE-W & 40.2583 & 141.1744 & 225 & 100 \\
\hline IWTH07 & KARUMAI & 40.2678 & 141.5744 & 260 & 120 \\
\hline IWTH08 & KUJI-N & 40.2658 & 141.7867 & 175 & 100 \\
\hline IWTH09 & KUJI-S & 40.0833 & 141.7156 & 240 & 100 \\
\hline IWTH10 & ASHIRO & 40.1364 & 140.9564 & 308 & 100 \\
\hline IWTH11 & ICHINOHE & 40.0783 & 141.195 & 629 & 300 \\
\hline IWTH12 & KUNOHE & 40.1506 & 141.4281 & 365 & 100 \\
\hline IWTH13 & KUZUMAKI & 39.9369 & 141.5528 & 570 & 117 \\
\hline IWTH14 & TAROU & 39.7406 & 141.9125 & 200 & 100 \\
\hline IWTH15 & YAHABA & 39.6119 & 141.0964 & 195 & 122 \\
\hline IWTH17 & KAWAI-N & 39.6414 & 141.6013 & 305 & 103 \\
\hline IWTH18 & KAWAI-S & 39.46 & 141.6806 & 552 & 100 \\
\hline IWTH19 & HANAMAKI-N & 39.4531 & 141.0036 & 220 & 101 \\
\hline IWTH20 & HANAMAKI-S & 39.3406 & 141.0508 & 106 & 156 \\
\hline IWTH21 & YAMADA & 39.4706 & 141.9372 & 13 & 100 \\
\hline IWTH22 & TOUWA & 39.3311 & 141.305 & 260 & 100 \\
\hline IWTH23 & KAMAISHI & 39.2717 & 141.8267 & 44 & 103 \\
\hline IWTH24 & KANEGASAKI & 39.195 & 141.0153 & 200 & 150 \\
\hline IWTH25 & ICHINOSEKI-W & 39.0061 & 140.8667 & 386 & 260 \\
\hline IWTH26 & ICHINOSEKI-E & 38.9661 & 141.0047 & 125 & 108 \\
\hline IWTH27 & RIKUZENTAKATA & 39.0278 & 141.5356 & 80 & 100 \\
\hline MYGH01 & SENDAI & 38.237 & 141.0003 & 2 & 1206 \\
\hline MYGH02 & NARUKO & 38.8558 & 140.6547 & 345 & 203 \\
\hline MYGH03 & KARAKUWA & 38.9189 & 141.6422 & 50 & 117 \\
\hline MYGH04 & TOUWA & 38.7831 & 141.3289 & 35 & 100 \\
\hline MYGH05 & ONODA & 38.5764 & 140.7839 & 59 & 337 \\
\hline MYGH06 & TAJIRI & 38.5878 & 141.0744 & 20 & 100 \\
\hline MYGH07 & KAWASAKI & 38.1772 & 140.6439 & 186 & 142 \\
\hline MYGH08 & IWANUMA & 38.1103 & 140.8475 & 10 & 100 \\
\hline MYGH09 & SHIROISHI & 38.0061 & 140.6061 & 130 & 100 \\
\hline MYGH10 & YAMAMOTO & 37.9381 & 140.8958 & 18 & 205 \\
\hline MYGH11 & KAHOKU & 38.5131 & 141.3456 & 5 & 207 \\
\hline MYGH12 & SHIZUGAWA & 38.6386 & 141.4463 & 18 & 102 \\
\hline
\end{tabular}

Table 2

Event Information Used in This Study

\begin{tabular}{llccc}
\hline Date (MM/DD/YY) & $M_{\mathrm{w}}$ & Longitude (deg) & Latitude (deg) & Depth $(\mathrm{km})$ \\
\hline $05 / 26 / 03,22: 34$ & 4.6 & 141.6 & 38.89 & 76 \\
$05 / 27.03,00: 44$ & 4.7 & 141.66 & 38.95 & 69 \\
$05 / 27 / 03,10: 47$ & 4.5 & 141.68 & 38.75 & 66 \\
$05 / 27 / 03,13: 11$ & 4.5 & 141.68 & 38.74 & 66 \\
$05 / 27 / 03,21: 12$ & 4 & 141.64 & 38.96 & 68 \\
$05 / 28 / 03,6: 24$ & 4.5 & 141.62 & 38.85 & 73 \\
$05 / 31 / 03,1: 33$ & 4 & 141.62 & 38.78 & 68 \\
$05 / 31 / 03,18: 42$ & 4.7 & 141.62 & 38.85 & 74 \\
$06 / 01 / 03,5: 38$ & 4.2 & 141.61 & 38.86 & 74 \\
$06 / 10 / 03,16: 24$ & 4.8 & 141.67 & 38.93 & 67 \\
$06 / 28 / 03,20: 19$ & 4.3 & 141.58 & 38.81 & 72 \\
$07 / 14 / 03,7: 30$ & 4.1 & 141.66 & 38.87 & 70 \\
$07 / 18 / 03,12: 32$ & 4.4 & 141.59 & 38.28 & 75 \\
$07 / 21 / 03,19: 04$ & 4.3 & 141.61 & 38.8 & 71 \\
\hline
\end{tabular}

Epicenters are depicted as triangles in Figure $1 b$. celeration time histories will be used in the ensuing. Note that the event selection criterion ensures both adequate SNR and acceleration amplitude low enough to allow the material response to be realistically represented by means of a viscoelastic-layered medium. The hypocenter latitude, longitude, and depth, as well as the event magnitude and time of occurrence, are listed in Table 2, while their epicentral locations are depicted by the triangles in Figure $1 b$.

The global-local optimization scheme was applied in series for the ensemble of events at each station, and the optimal soil configuration was estimated by averaging the individual best-fit soil configurations. For each event, the signal processing of the borehole and surface records comprised the following steps: (1) computation of the transverse motion at all receiver depths by rotating the north-south and east-west seismogram components through the great circle path based on the event and receiver coordinates, (2) denoising of the rotated components by applying an energy 
threshold equal to 5\% of the maximum spectral amplitude level, and (3) filtering using a Butterworth filter with a passband $(1-15 \mathrm{~Hz})$. Successively, the SNR of the rotated, denoised, and filtered seismograms is computed, and the four events with higher signal quality per station were selected for the inversion of the low-strain dynamic soil properties at stations $1-5$.

Accounting for the fact that large events have longer source durations than smaller ones, the appropriate amount of digital information (i.e., seismogram time window) to be used in the optimization scheme was defined as a function of the event's magnitude. Following Abercrombie (1997), we use 1-sec windows for small events $\left(M_{\mathrm{L}}<3\right), 2$-sec windows for events $3<M_{\mathrm{L}}<4$, and 4-sec windows for the larger events. It should be noted that the selection of the appropriate time window is a trade-off between data misfit assessment points in the inversion scheme and excess information that cannot be reproduced by the forward mathematical model. While using long time windows ensures a robust estimation of the average empirical site response, hysteretic energy absorption and late arrivals of scattered energy are being simultaneously modeled through a mathematical operator that only describes vertically propagating upgoing and downgoing waves, thus reducing the accuracy of the estimated attenuation structure.

An example of the inversion scheme output, namely the average optimum soil structure obtained using multiple events at station MYGH04, is illustrated in Figure 2a. Also shown is the shear-wave velocity structure at the site that was obtained from a geophysical site investigation as well as empirical estimates of the local attenuation and density profiles that were used to seed the initial generation of the optimization scheme. Note that the use of available geotechnical information (i.e., a potentially good solution) as one of the randomly generated parameter vectors of the first parental population accelerates convergence of the genetic algorithm because the stochastic search by default improves iteratively existing models (i.e., estimates obtained through heuristic methods and/or current practices).

As can be readily seen, the inverted shear-wave velocity $\left(V_{s}\right)$ structure does not deviate substantially from the coarsely reported geophysical data despite the refined discretization of the continuum used within the context of the inverse analysis, which is typically $1 / 4$ of the reported layer thickness. Furthermore, as expected, the density structure is very similar to one estimated on the basis of the available geotechnical information. A comparison of the surface measured and synthetic waveforms for the 2-sec time window used in the optimization process, computed when the average optimum shear-wave velocity, attenuation, and density profile are subjected to the total motion recorded at the borehole level during four aftershock events, is shown in Figure $2 \mathrm{~b}$. As can be readily seen, the hybrid stochasticdeterministic optimization scheme may depict refined varia- (a)

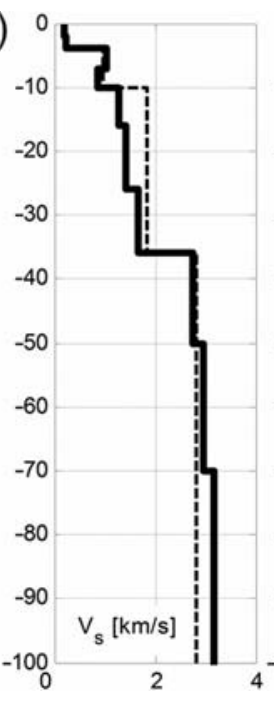

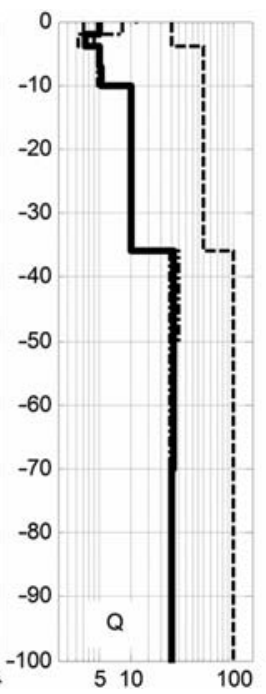

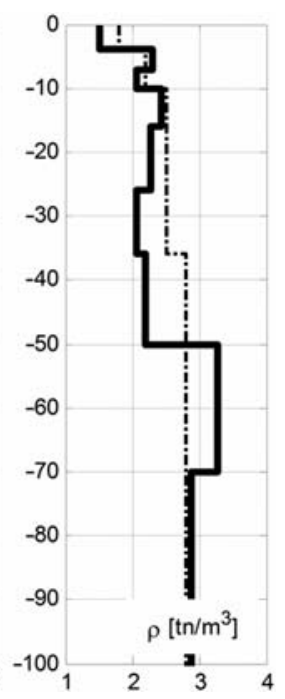

(b)

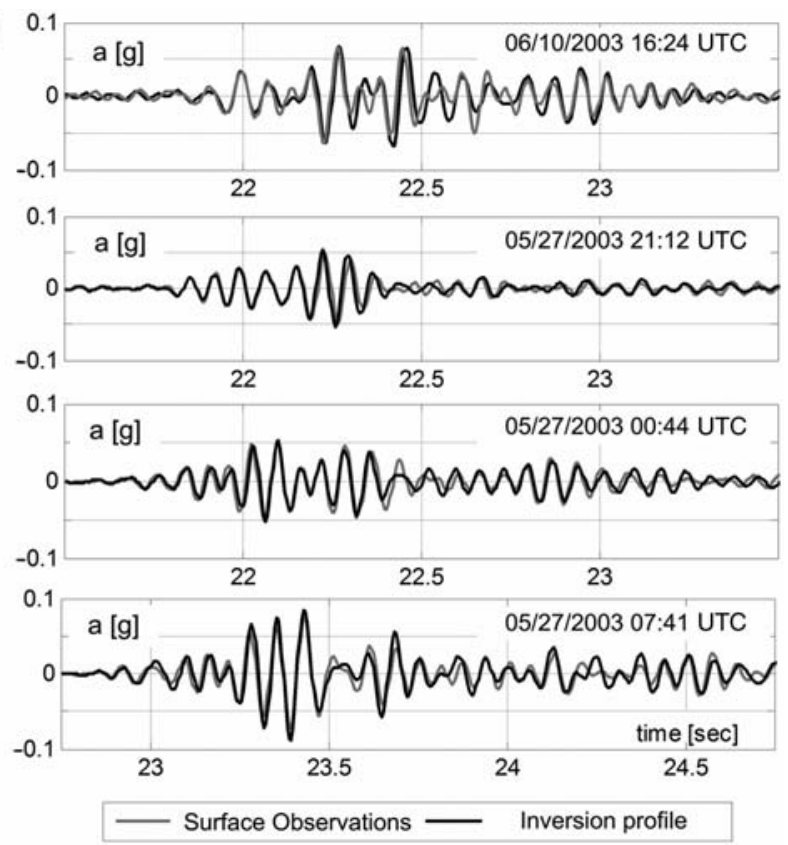

Figure 2. (a) Mean inverted shear-wave velocity, attenuation, and density structures at station MYGH04 using weak-motion events (here shown the four seismograms at the surface station corresponding to motions with the highest SNR); also shown is the shear-wave velocity from geophysical site investigation and empirical estimates of local attenuation and density used in conjunction with the local site investigation information to seed the first parental generation with potentially good solutions. (b) Comparison of surface observations and synthetics computed on the basis of the average global optimum profile shown in (a) for four aftershock events recorded at station MYGH04. 
tions of the impedance and attenuation soil structures, resulting in accurate representation of both the frequency content and amplitude of the recorded surface-ground motion.

\section{Velocity-Attenuation Correlations in the Near Surface}

The NEHRP code provisions (BSSC, 2001) and site conditions are parameterized on the basis of the average shearwave velocity in the upper $30 \mathrm{~m}$ of the site $\left(V_{s 30}\right)$, and are defined as the ratio of $30 \mathrm{~m}$ to the vertical shear-wave travel time through the upper $30 \mathrm{~m}$ of the site, namely,

$$
V_{s 30}=30[\mathrm{~m}] / \sum_{i=1}^{n} \frac{h_{i}[\mathrm{~m}]}{V_{s i}[\mathrm{~m} / \mathrm{sec}]},
$$

where $n$ is the number of layers of the profile, $h_{i}$ is the thickness of the $i$ th layer, and $V_{s i}$ is the shear-wave velocity of the $i$ th layer. Based on the aforementioned classification system, site effects are accounted for to improve the accuracy of ground-motion predictions in seismic hazard analyses, either by adjustment of probabilistic seismic hazard analysis (PSHA) predictions with amplification factors or by means of site-specific geotechnical analyses of local ground response effects. The $V_{s 30}$-based site categories suggested by the NEHRP provisions are given in Table 3.

The inverted shear-wave velocity $\left(V_{s}\right)$ profiles, estimated at $37 \mathrm{KiK}-\mathrm{Net}$ geotechnical array sites by means of the hybrid downhole array algorithm, were initially for the classification of site conditions in accordance to the NEHRP $V_{s 30}$ categorization system, and the effectiveness of the alternative site amplification estimates described in the ensuing was assessed as a function of the corresponding site class. The $V_{s 30}$-based site classification of the profiles investigated in this study is presented in Table 4, which comprise 7 class B sites $\left(V_{s 30}=760-1500 \mathrm{~m} / \mathrm{sec}\right), 21$ class $\mathrm{C}$ sites $\left(V_{s 30}=360-760 \mathrm{~m} / \mathrm{sec}\right)$, and 9 class D sites $\left(V_{s 30}=180-\right.$ $360 \mathrm{~m} / \mathrm{sec}$ ).

Table 3

NEHRP Site Classification System of Soil Conditions

\begin{tabular}{clc}
\hline $\begin{array}{c}\text { NEHRP } \\
\text { Category }\end{array}$ & \multicolumn{1}{c}{ Description } & $\begin{array}{c}\text { Mean Shear-Wave Velocity } \\
\text { to } 30 \mathrm{~m}\end{array}$ \\
\hline A & Hard rock & $>1500 \mathrm{~m} / \mathrm{sec}$ \\
B & Firm to hard rock & $760-1500 \mathrm{~m} / \mathrm{sec}$ \\
C & Dense soil, soft rock & $360-760 \mathrm{~m} / \mathrm{sec}$ \\
D & Stiff soil & $180-360 \mathrm{~m} / \mathrm{sec}$ \\
E & Soft clays & $<180 \mathrm{~m} / \mathrm{sec}$ \\
F & Special study soils (e.g., \\
& liquefiable & \\
& soils, sensitive clays, \\
& organic soils, & \\
& soft clays $>36$ m thick)
\end{tabular}

The conditions are measured as a function of the weighted average shearwave velocity in the upper $30-\mathrm{m}$ of the profile. Information in this table is taken from Dobry et al., 2000.
Table 4

Site Classification of Soil Conditions Investigated in This Study

\begin{tabular}{|c|c|c|}
\hline Station Code & $V_{s 30}$ & Site Class \\
\hline MYGH01 & 239 & $\mathrm{D}$ \\
\hline IWTH20 & 278 & D \\
\hline MYGH02 & 294 & $\mathrm{D}$ \\
\hline MYGH05 & 303 & $\mathrm{D}$ \\
\hline IWTH08 & 312 & $\mathrm{D}$ \\
\hline IWTH12 & 317 & $\mathrm{D}$ \\
\hline MYGH07 & 321 & $\mathrm{D}$ \\
\hline IWTH02 & 350 & $\mathrm{D}$ \\
\hline IWTH15 & 351 & $\mathrm{D}$ \\
\hline IWTH11 & 361 & $\mathrm{C}$ \\
\hline IWTH26 & 381 & $\mathrm{C}$ \\
\hline IWTH06 & 397 & $\mathrm{C}$ \\
\hline IWTH01 & 398 & $\mathrm{C}$ \\
\hline IWTH07 & 424 & $\mathrm{C}$ \\
\hline IWTH05 & 436 & $\mathrm{C}$ \\
\hline IWTH19 & 438 & $\mathrm{C}$ \\
\hline IWTH16 & 448 & $\mathrm{C}$ \\
\hline IWTH25 & 451 & $\mathrm{C}$ \\
\hline IWTH24 & 455 & $\mathrm{C}$ \\
\hline MYGH08 & 457 & $\mathrm{C}$ \\
\hline IWTH27 & 475 & $\mathrm{C}$ \\
\hline IWTH04 & 497 & $\mathrm{C}$ \\
\hline IWTH22 & 509 & $\mathrm{C}$ \\
\hline IWTH21 & 580 & $\mathrm{C}$ \\
\hline IWTH10 & 592 & $\mathrm{C}$ \\
\hline MYGH06 & 617 & $\mathrm{C}$ \\
\hline IWTH13 & 645 & $\mathrm{C}$ \\
\hline IWTH18 & 721 & $\mathrm{C}$ \\
\hline IWTH14 & 721 & $\mathrm{C}$ \\
\hline MYGH11 & 737 & $\mathrm{C}$ \\
\hline MYGH04 & 775 & B \\
\hline IWTH03 & 829 & B \\
\hline IWTH23 & 853 & B \\
\hline MYGH12 & 1025 & B \\
\hline MYGH03 & 1026 & B \\
\hline IWTH09 & 1032 & B \\
\hline IWTH17 & 1223 & B \\
\hline
\end{tabular}

This study comprises 7 class B sites $\left(V_{s 30}=760\right.$ $1500 \mathrm{~m} / \mathrm{sec}), 21$ class $\mathrm{C}$ sites $\left(V_{s 30}=360-760 \mathrm{~m} / \mathrm{sec}\right)$, and 9 class $\mathrm{D}\left(V_{s 30}=180-360 \mathrm{~m} / \mathrm{sec}\right)$ sites.

While unconsolidated or poorly consolidated sediments may cause significant amplification of seismic ground motion, energy attenuation in sediments can be high as well, thus contributing to a decrease in ground-motion amplitudes. Therefore, a reliable estimate of seismic attenuation, in addition to the site conditions described by means of the $V_{s}$ variation in the near surface, is critical for the realistic assessment of the seismic hazard in sedimentary deposits. Nonetheless, in situ reliable measurements of attenuation in the near surface (quantified in terms of the inverse quality factor $Q_{s}$ ) are very rarely employed in practice due to the difficulties associated with their conduction and corresponding interpretation of field and laboratory results. In particular, the complexity of the problem is increased by the multitude of physical mechanisms that affect the amplitude and frequency content of seismic waves, which include, among others, the intrinsic attenuation, seismic energy redistribution 
(scattering), and wave reverberation in highly heterogeneous near-surficial layers.

Noninvasive surface-wave methods are perhaps the most widely known field site characterization techniques that have been recently employed for the estimation of near-surface seismic energy attenuation. Based on the geometric dispersion of Rayleigh waves in heterogeneous media, and originally developed for determining the impedance profile of soil deposits and pavement systems, surface-wave tests have also recently been used to determine the intrinsic attenuation of soil deposits (Lai, 1998; Foti and Lai, 1999; Rix et al., 2000) thereby providing important information for the complete characterization of small-strain dynamic properties at a site. To this end, a number of authors have pursued, with various degrees of rigor, coupled viscoacoustic interpretations of the waveforms in attenuating media (Chaderjian, 1994; Causse et al., 1999), and more closely related to the viscoelastic inversion techniques for soil attenuation in the near surface, one should also mention the work on one-dimensional (1D) seismic reflection analysis by Martinez and McMechan (1991) and the 3D spectral interpretation of surface motion in a layered solid due to impact load (Stubbs et al., 1994; Uzan, 1994). It should be noted that all the previously described methodologies are centered around gradient-based minimization algorithms owing to the prohibitive computational cost of random search techniques for this class of problems.
Recently, Guzina and Lu (2002) developed a method based on an analytical 3D wave-propagation model for a uniform viscoelastic half-space, which simultaneously resolves the material stiffness, damping, and density via suitable matching between the predicted and observed frequency response functions synthesizing the surface motion. Nonetheless, the applicability of the method has not been illustrated for layered media or spatially varying formations. Nonetheless, while profiling results evaluated by means of surface-wave and invasive methods are typically in agreement, discrepancies do arise (Brown et al., 2002), primarily for cases characterized by O'Neill (2003) as stiffover-soft geology, interbedded soft layers, and hard, buried horizons.

Alternatively, ambient vibration measurements that have been consistently employed for the evaluation of velocity profiles have been shown to yield unsatisfactory results for the assessment of near-surface attenuation, primarily due to the wave field complexity associated with the forward representation these measurements (e.g., Matsushima and Okada, 1990a,b; Horike, 1993; Tokimatsu, 1997; Tokimatsu et al., 1998; Arai and Tokimatsu, 2000; Scherbaum et al., 2003). Finally, forced vibration-based techniques based on impedance function determination in situ (Luco and Wong, 1986) that have allowed the identification of impedance and Poisson's ratios of soil profiles have been shown to yield erratic and unrealistic attenuation values.

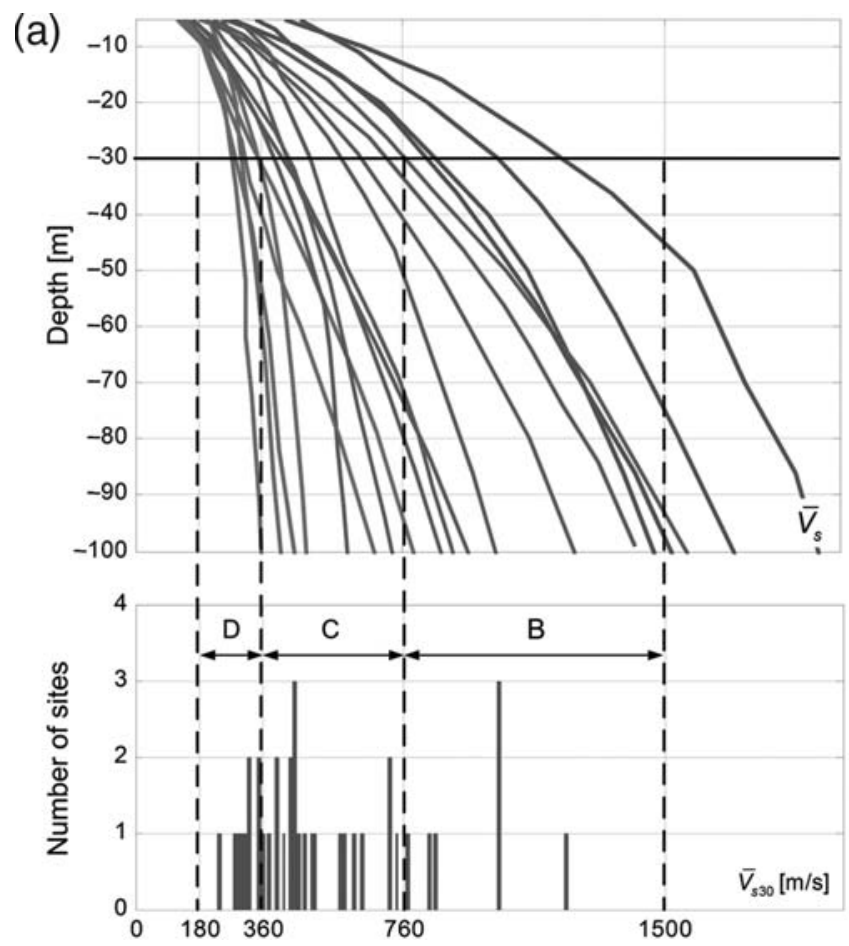

Figure 3. (a) Site classification of profiles investigated as a function of the weighted average shear-wave velocity in the top $30 \mathrm{~m}\left(V_{s 30}\right)$ of the profiles. (b) Shear-wave velocity $\left(V_{s}\right)$, attenuation $(Q)$, and density $(\rho)$ profiles evaluated at 37 stations of the Japanese strong-motion network KIK-Net by means of downhole array seismogram inversion of aftershock observations obtained during the Myiagi-Oki 2003 sequence, classified as a function of the weighted average shear-wave velocity in the near surface (see [a]). Top: 9 class B sites. Middle: 21 class $\mathrm{C}$ sites. Bottom: 7 class D sites. 
Compared to noninvasive field investigation techniques, attenuation values obtained using in situ borehole recordings may provide critical constrains on the physical mechanisms of energy absorption and redistribution in the near surface due to the minimization of uncertainty introduced in the inversion forward operator by the a priori knowledge of the total wave field at the borehole level of the site under investigation. Constraining the underlying physics in the forward-model operators could substantially improve future estimates of near-surface attenuation obtained via
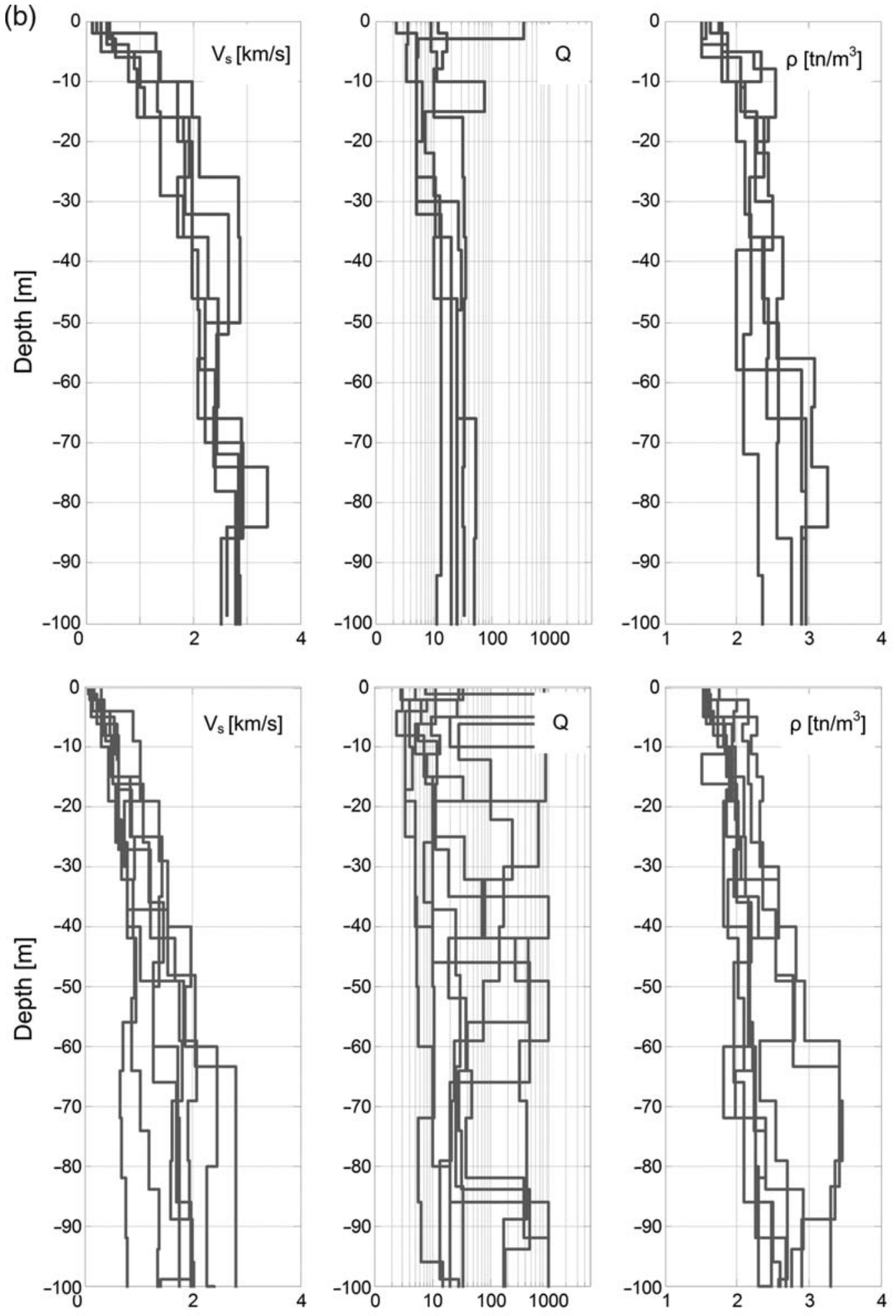

Figure 3. Continued. 

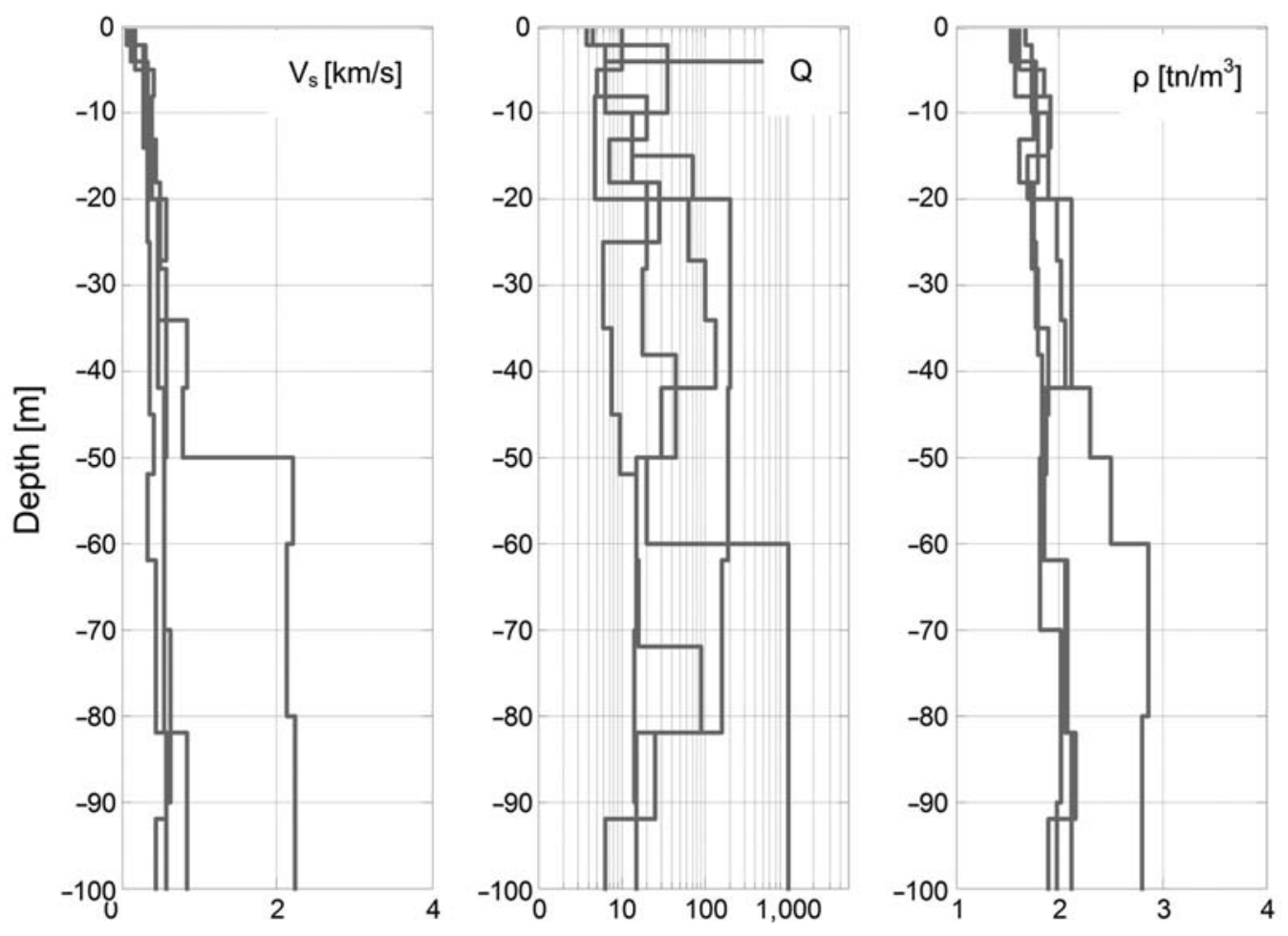

Figure 3. Continued.

surface-wave measurements or ambient noise recordings. Typical studies of borehole measurements for the assessment of attenuation values include, among others, Kudo and Shima (1970), who investigated attenuation in four boreholes about 40-50 m deep in Tokyo, and several more recent $Q_{s}$ values that have been reported for typical sites in California by Gibbs and Roth (1989), Gibbs et al. (1994), Abercrombie (1997), and Wald and Mori (2000).

Figure $3 b$ illustrates the velocity, attenuation, and density structures for the ensemble of downhole array sites, categorized in three NEHRP site classes as a function of their estimated $V_{s 30}$. The inverted profiles depicted in this figure were evaluated based on 10 weak-motion seismogram recordings at each site, conditioned on the fulfilment of the magnitude $\left(M_{\mathrm{w}}\right)$ and SNR criteria described previously. Optimization analyses were conducted in series for each profile, global optima of soil-property vectors were obtained, and finally, the velocity-, attenuation-, and density-inverted structures were averaged across the multiple events to evaluate the best-fit soil profiles while minimizing the error propagation from the measured data and the limitations of the forward-model operator.

Correlation between soil layer shear-wave velocity $\left(V_{s}\right)$ and attenuation $\left(Q_{S}\right)$ in the near surface, extracted from the seismogram inversion results, is next illustrated in Figure 4. In particular, the figure depicts the $V_{s}-Q_{s}$ relationship for the entire depth of the profiles investigated, the upper $30 \mathrm{~m}$ of the profiles and the resulting weighted average velocity and at- tenuation in upper $30 \mathrm{~m}$ of the profiles. Similarly to the definition of weighted average shear-wave velocity in the near surface $\left(V_{s 30}\right)$, the weighted average attenuation in shear $\left(Q_{30}\right)$ is defined here as

$$
Q_{30}=30[\mathrm{~m}] / \sum_{i=1}^{n} \frac{h_{i}[\mathrm{~m}]}{Q_{i}},
$$

where $Q_{i}$ is the quality factor in shear $\left(Q_{s}\right)$ of the $i$ th layer. The correlations depicted in Figure 4, namely the highly scattered relationship between shear-wave velocity and attenuation in the upper $100 \mathrm{~m}$ of the soil profiles, the bounded increase of $Q_{s}(<20)$ as a function of $V_{s}$ in the near surface (upper $30 \mathrm{~m}$ ), and the inversely proportional $V_{s 30}-Q_{30}$ relationship, are attributed to scattering effects of the incident seismic energy in the strongly heterogeneous surficial soil layers. Even further, the attenuation values close to the surface were found to be quite substantial when compared to published laboratory measurements of low amplitude dynamic soil properties (typically on the order of $Q_{s}=$ 15-50 for stiff sedimentary formations). Stemming directly from the use of relatively short time windows in conjunction to a viscous mathematical model representing both hysteretic energy absorption and scattering energy redistribution, this result is also attributed to scattering effects of seismic energy in the near surface: late arrivals of scattered energy not included in the inverted physical process are interpreted by the forward operator as energy loss, thus rendering, in some 

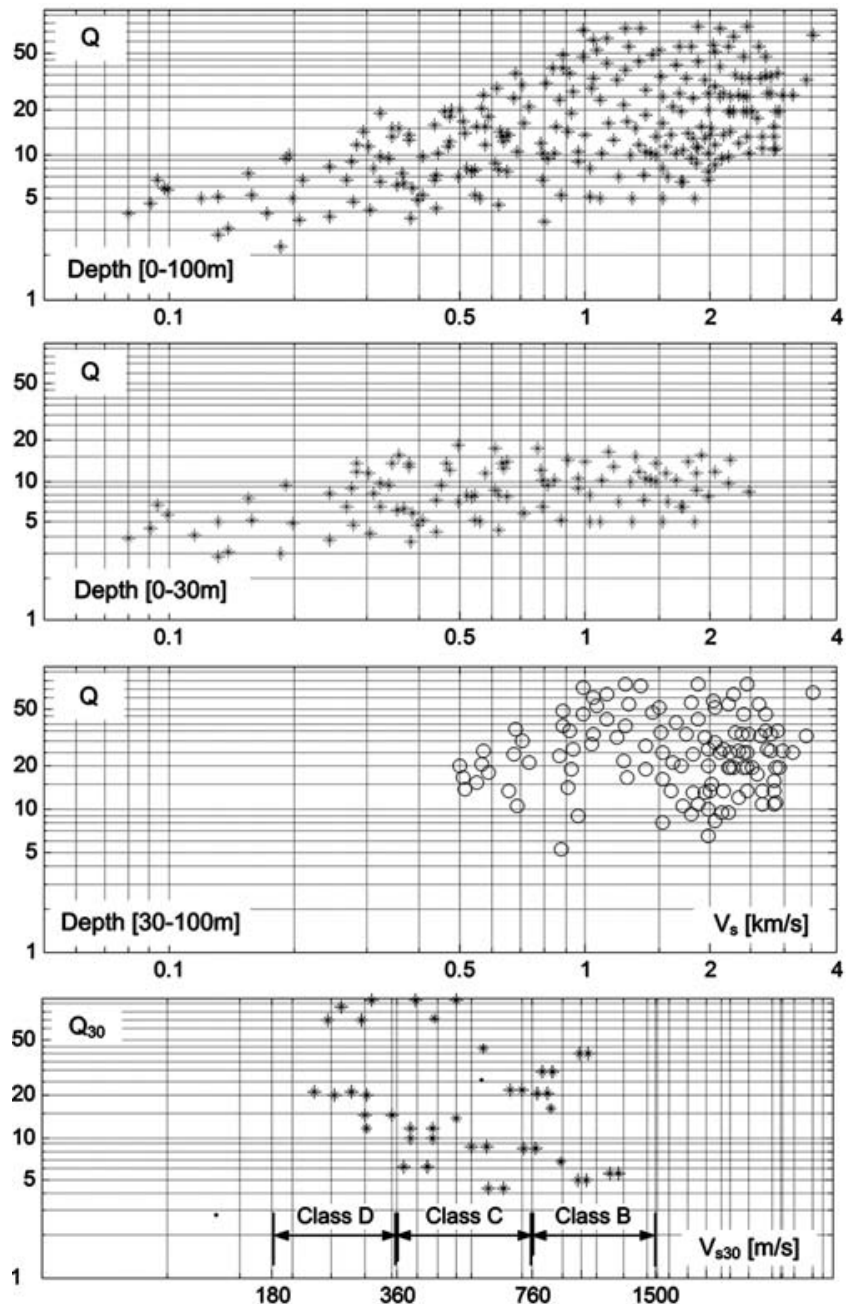

Figure 4. Correlation between soil layer shear-wave velocity $\left(V_{s}\right)$ and attenuation $(Q)$ in the near surface, extracted from the seismogram inversion results of the entire depth of the profiles investigated (top), the upper $30 \mathrm{~m}$ of the profiles (middle), and the deeper layers of the profile (30-100), as well as the resulting weighted average velocity and attenuation in the near surface (bottom). The relationships depicted in the middle and latter figures, namely the bounded increase of $Q<20$ as a function of $V_{s}$ and the inversely proportional $V_{s}-Q$ trend are attributed to scattering effects of the incident seismic energy in the strongly heterogeneous superficial soil layers.

cases, the estimated attenuation values unrealistically high for the anticipated linear material behavior.

To illustrate this concept, Figure 5 depicts the temporal variability of the empirical transfer function recorded at station MYGH04 during the $M_{\mathrm{w}} 4.6$ event (26 May 2003, 22:34 UTC); seismogram inversion results for this station have been already illustrated in Figure 2. For this purpose, a 2.2-sec, 5\% tapered sliding window is applied, and the surface borehole frequency spectra and corresponding empirical transfer functions are computed. The latter is estimated as the amplitude of the complex Fourier spectral ratio of the surface-to-borehole motion. As can be readily seen, the rela- tively uniform site response, which corresponds to the first $S$-wave arrival $(T=22.20 \mathrm{sec})$, is followed by a highly erratic region. Unlike the former, the response is here governed by late arrivals of scattered energy interacting with waves trapped within the strongly heterogeneous, nearsurficial layers. For a detailed description of the effects of scattering on the inverted attenuation structure, the reader is referred to Assimaki et al. (2006).

As can be readily seen, the observed highly erratic behavior of velocity-attenuation relationships stems directly from the multitude of physical attenuation mechanisms represented herein by means of a simplified forward wavepropagation model. This effect, in turn, does not allow the establishment of credible correlations for the geographically greater region investigated on the level of detailed description required by broadband ground-motion models in the near surface. Even further, attempting to a coarser description of the velocity-attenuation correlation in the near surface by means of a homogeneously attenuating medium in the upper $30 \mathrm{~m}$ (Fig. 4) results in an inversely proportional relationship between the two quantities, which in fact contradicts typically reported data of increasing $Q_{s}$ with increasing soil stiffness. Our results, corroborated by recently reported data by Pujol et al. (2002) for the Mississippi embayment sediments, lead to the conclusion that the site lithology, stratification, and randomness significantly affect attenuation estimates in the near surface. As a result, velocity-attenuation correlations obtained by means of simplified models simulating the complex multitude physical mechanisms of energy absorption and redistribution in the upper few hundreds of meters of the crust may not be employed to extrapolate attenuation profiles in adjacent sites due to the highly heterogeneous nature of soil materials at these depths.

\section{Comparison of Single and Reference-Station Site-Amplification Estimates}

Quantification of ground-motion site amplification is a key component in mapping seismic hazards in urban areas (e.g., Frankel et al., 2000) and has been traditionally expressed by means of spectral ratios, namely ratios of the Fourier amplitude spectra of a soil-site record to that of a nearby rock-site record (Borcherdt, 1970). Despite the fact that (1) direct $S$-wave recordings often consist of a limited data set when compared to coda-wave observations due to the saturation of microearthquake observation networks at the time of first ground-motion arrivals (Phillips and Aki, 1986; Su and Aki, 1990; Chin and Aki, 1991), and (2) many of the stations in seismogram networks consist of singlecomponent high-gain vertical sensors, which are not optimally oriented to record direct $S$ waves, advancements in the instrumentation technology and acquisition of high-quality data from new events in the recent years have rendered $S$-wave spectral ratios widely employed for the estimation of site amplification spectra (Hartzell, 1992; Margheriti et al., 1994; Field and Jacob, 1995; Field, 1996; Hartzell et al., 

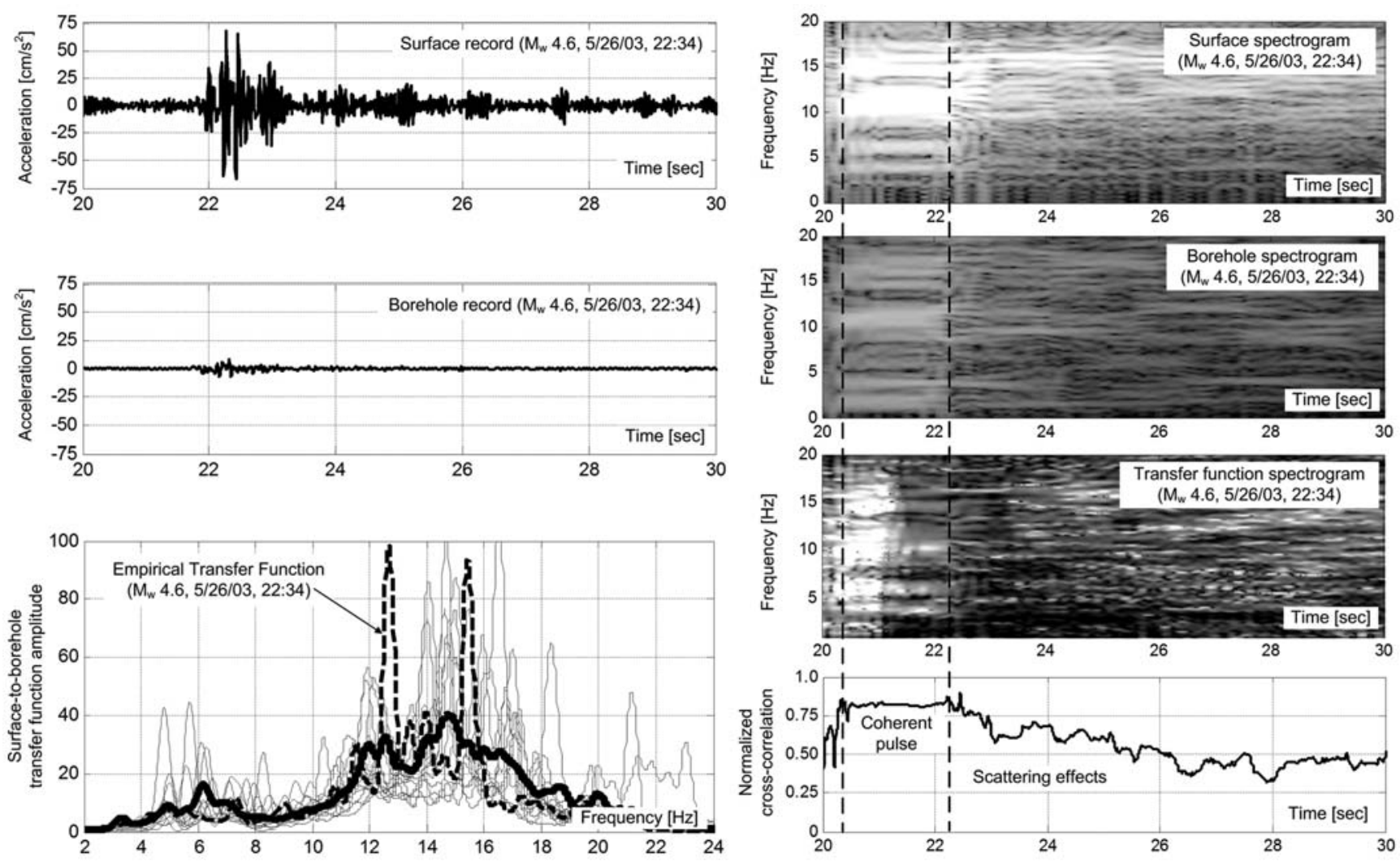

Figure 5. Surface (top left) and borehole (middle left) recorded acceleration time histories at station MYGH04 during the $M_{\mathrm{w}} 4.6$ event on 26 May 2003 (22:34 UTC) and their corresponding time-history spectrograms evaluated for a sliding 2.2-sec window (top right); transfer function amplitude spectrogram (middle right) evaluated for the same event as the complex ratio of the surface-to-borehole spectrogram functions, and average transfer function evaluated as the cross-spectral ratio for a 5-sec window depicted by the dashed line on the lower left figure (also shown are the transfer functions of the ensemble of events recorded at station MYGH04 and used in this study, as well as the average transfer function at the station depicted by the bold black line); finally, evolution of the surface-to-borehole cross-correlation function (bottom right) for the same event, illustrating the regions of the spectrum dominated by the two mechanisms of attenuation, namely energy absorption in the coherent region and scattering in the later arrivals of incident seismic energy.

1996; Su et al., 1996). The spectral ratio method, however, depends on the availability of an appropriate reference site, namely a site with negligible site response. The fact that the existence of such a site is not always granted has led to the development of alternate techniques called non-referencesite methods, which have been employed for site-response studies in absence of reference-site recordings. One of these methods to estimate site response uses the spectral ratio between the H/V spectra of the $S$-wave window for each site (Lermo and Chávez-García, 1993).

The effectiveness of reference-site and single-station site amplification techniques is evaluated in this study using data from the 2003 Miyagi-Oki aftershock sequence. A brief description of the alternative techniques is presented in the ensuing, while a schematic illustration of the alternative estimators is depicted in Figure 6. These include surface-toborehole traditional spectral ratios and cross-spectral ratios, horizontal-to-vertical site-response estimates on ground surface, and surface-to-rock outcrop transfer functions (esti- mated from the borehole motion by deconvolution and upward propagation using the global optimum inverse profile).

Following Douglas (2003), accurate representation of the horizontal motion is evaluated here by treating the horizontal time histories as $2 \mathrm{D}$ signals following a complex time series, as follows:

$$
a_{H}(t)=a_{\mathrm{NS}}(t)+i a_{\mathrm{EW}}(t)
$$

where $a_{\mathrm{NS}}(t), a_{\mathrm{EW}}(t)$, and $a_{H}(t)$ represent the north-south, east-west, and complex horizontal components of the accelerogram, respectively. As a result, the amplitude spectrum of the complex time series $a_{H}(t)$ provides the total amplitude of horizontal motion at a given frequency while preserving the phase between components and requires the estimation of a single fast Fourier transform without consideration of the orientation of the components. Considering the advantages of this approach, the ensemble of site-response estimates 


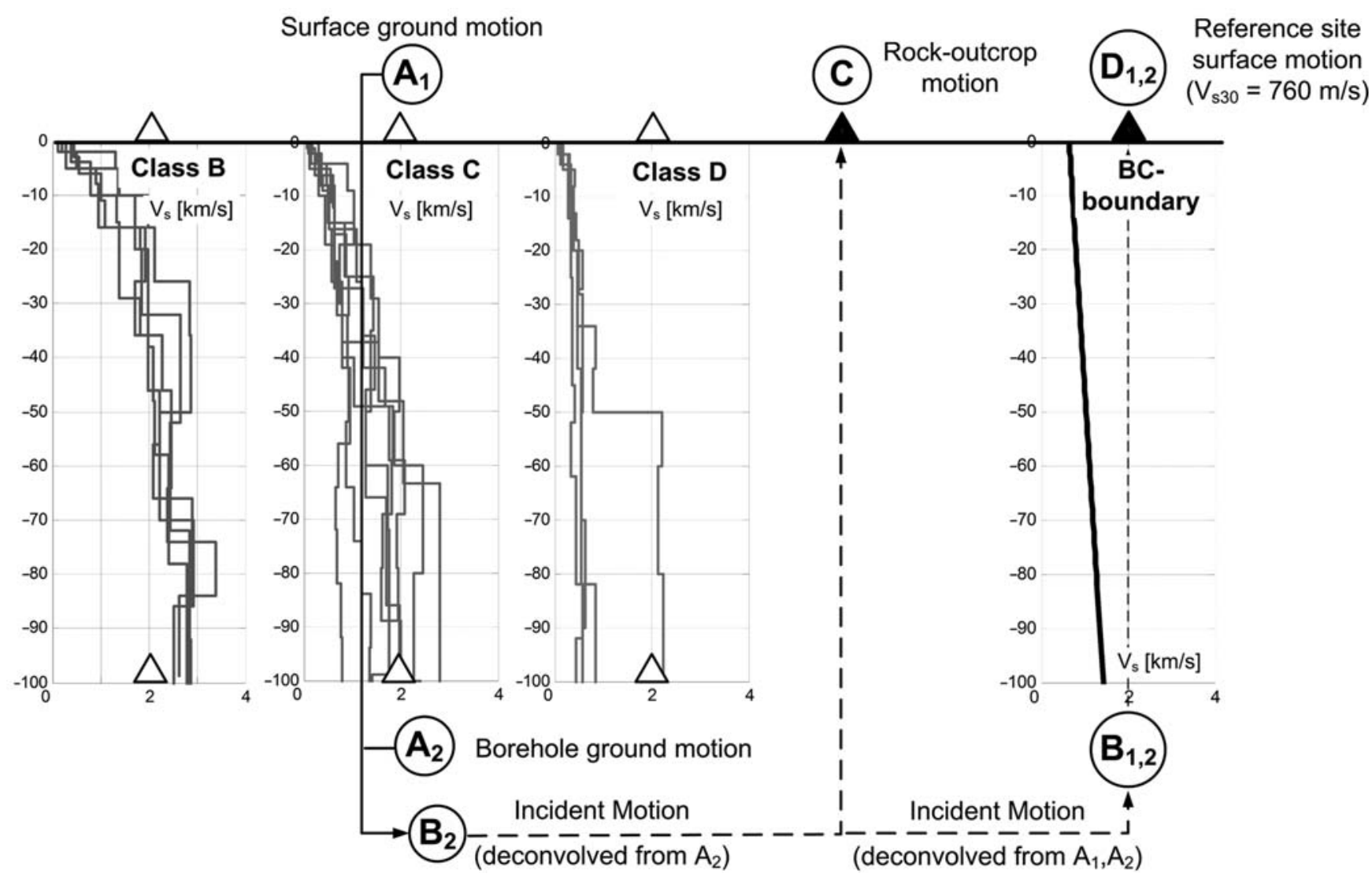

Figure 6. Schematic illustration of site amplification estimates compared in this study, namely the surface-to-borehole transfer function and cross-spectral ratio $\left(A_{1} / A_{2}\right)$, the horizontal-to-vertical site-response estimate $\left(\mathrm{H} / \mathrm{V} A_{1}\right)$, and the surface-to-rock outcropping (deconvolved from $\left.A_{2}\right)$ transfer function $\left(A_{1} / C\right)$. Also, schematic illustration of the empirical site amplification factors, evaluated as the average response spectral ratio of the surface $\left(A_{1}\right)$ to the reference-site ground motion, the latter derived via deconvolution of the surface $\left(A_{1}\right)$ or the borehole $\left(A_{2}\right)$ recorded motion correspondingly.

are evaluated here by means of this complex representation of horizontal motion.

Successively, 10 -sec time windows starting 2 sec prior to the arrival of $S$ waves were selected for the evaluation of site amplification estimates, computed by means of a sliding 5 -sec, 5\% Hanning-tapered window with 1.25 -sec overlap. According to Steidl et al. (1996), the window used for the evaluation of the $S$-wave site-response spectral ratios is a subjective choice made at the time of analysis because larger events have longer durations of $S$-wave energy, and while the length of the selected time window defines the frequency resolution in the spectra, earthquake records are highly nonstationary, which implies that their frequency content changes with time. In particular, the frequencies at the beginning of the record originate primarily from the source rupture, namely a random process, while the frequency content of later arrivals is controlled by scattering effects and filtering by the local geology (Safak, 1997). This nonstationary nature of seismogram recordings, aggravated by potential amplitude-dependent nonlinearities exhibited by the soil formations, result in the observed variability in spectral ratios calculated by using different portions of the records. Ac- counting for the nonstationarity of seismogram recordings and the target-frequency-domain resolution of spectral ratios computed in the ensuing, implementation of a 5-sec sliding window for the evaluation of the Fourier spectra was selected in this study to minimize the signal randomness in the highfrequency region, which originates from data contamination due to noise and from scattering effects in the near surface.

Smoothing is finally employed to reduce the effects of noise on spectral ratios. For the selection of the appropriate smoothing window, a preliminary optimization analysis was conducted for selected records, in which characteristic measures of the spectral ratio (the average amplitudes in the 1-3-, 3-5-, and 5-7-Hz windows) were plotted against increasing window lengths. According to Safak (1997), this curve is characterized by a sharp initial decay followed by a relatively flat region, and the optimal smoothing window is the window length corresponding to the beginning of the flat region, namely, the window beyond which the spectral ratio amplitudes are shown to be relatively insensitive to further increases of the window length. For this study, a $0.25-\mathrm{Hz}$ smoothing window was selected for the ensemble of seismic records processed. 


\section{Reference-Station Site-Amplification Estimates}

According to Borcherdt (1970) and Borcherdt and Gibbs (1976), the frequency content of a seismogram may be evaluated by convolving source, path and site effects, and the instrument response, and therefore, the spectral ratio obtained by the Fourier spectral ratio of the acceleration at a station $(j)$ by the spectrum at the reference station $(k)$ may be simplified as follows:

$$
\frac{A_{i j}(f)}{A_{i k}(f)}=\frac{S_{i}(f) \cdot P_{i j}(f) \cdot G_{j}(f) \cdot I_{j}(f)}{S_{i}(f) \cdot P_{i k}(f) \cdot G_{k}(f) \cdot I_{k}(f)}=\frac{G_{j}(f)}{G_{k}(f)}
$$

where $S_{i}(f)$ is the source term of the $i$ th event, $P_{i j}(f)$ is the path term between the $j$ th station and $i$ th event, $G_{j}(f)$ is the site term for the $j$ th station, and $I_{j}(f)$ is the instrumentresponse term for the $j$ th station. The formulation of this equation is conditioned on the following assumptions: (1) the spectral acceleration content of a single event will correspond to the same source term $S_{i}(f)$ for both the site and reference-site stations, provided that they are located at the same azimuth with respect to the source; (2) the instrument response is removed from the data prior to the estimation of site amplification; and (3) the separation distance between the site and reference-site stations is much smaller than the hypocentral distance from the source, resulting in practically common path terms. If condition (3) is not the case, a path geometrical spreading correction factor should be employed. A number of variations of the reference-site approach are described by Field and Jacob (1995), and the approach has been widely used (e.g., Boatwright, Fletcher, and Fumal, 1991; Boatwright, Seekins, and Mueller, 1991; Borcherdt and Glassmoyer, 1994; Harmsen, 1997; Hartzell et al., 1996; Borcherdt, 2002) despite the drawbacks associated with the selection of an appropriate reference site (Steidl et al., 1996).

Surface-to-Borehole Spectral Ratio (SSR). Among the ensemble of reference-station site amplification estimates, surface-to-downhole record spectral ratios could be considered as the ideal case for estimating site response when the borehole instrument is installed in a competent rock layer below the site of interest (Archuleta et al., 1992, 1993; Lu et al., 1992). Nonetheless, it has been shown that the motion recorded at the latter will contain downgoing reflected waves from the surface and other interfaces that can interfere with the upgoing incident wave field. Destructive interference between these waves at specific frequencies may therefore produce a local peak in the frequency spectrum of the borehole recording as has been shown in Shearer and Orcutt (1987) and Steidl et al. (1996). As a result, when shallow borehole data are used as reference for estimating amplification at the surface, the potential maximum in the borehole spectrum would produce peaks in the spectral ratios that could be misinterpreted as site-response peaks. Examples of artificial amplification peaks due to destructive inter- ference at the borehole instrument level are shown in the ensuing of this article.

Surface-to-Borehole Cross-Spectral Ratio (c-SSR). According to Steidl et al. (1996), destructive interference effects that manifest as artificial peaks in the empirical surfaceto-borehole transfer function correspond to sinks in the coherence estimate $C_{x y}(f)$ between the surface and borehole-recorded signals. Idealizing the soil profile under investigation as a homogeneous, undamped, medium soil layer of thickness $d$ overlaying rigid bedrock with shear-wave velocity equal to the weighted average velocity of the layered medium $\left(\bar{V}_{s}\right)$ between the surface and borehole instruments of the geotechnical array, namely,

$$
\bar{V}_{s}=\sum_{i=1}^{n}\left(V_{s i} h_{i}\right) / \sum_{i=1}^{n}\left(h_{i}\right)
$$

destructive interference between upgoing (incident) and downgoing (surface-reflection) waves will occur at the borehole instrument level at frequency $f_{\text {DI }}=\bar{V}_{s} / 4 d$, where $V_{s i}$ is the shear-wave velocity of the $i$ th layer of the medium, $h_{i}$ is the $i$ th layer thickness, and $d=\sum h_{i}$ is the surface-to-borehole distance.

Opting to investigate the occurrence of destructive interference effects and identify associated spurious resonant peaks in the surface-to-borehole site amplification, the magnitude-squared coherence estimate $C_{x y}(f)$ of the surface and borehole-recorded signals was evaluated in the ensuing by means of the Welch's averaged, modified periodogram method (Welch, 1967) defined as a function of the powerspectral density $P_{x x}(f), P_{y y}(f)$ and the cross-power spectral density $P_{x y}(f)$ of the observations as follows:

$$
C_{x y}(f)=\frac{\left|P_{x y}(f)\right|^{2}}{P_{x x}(f) P_{y y}(f)} .
$$

Successively, surface and downhole observations were used to evaluate the so-called cross-spectral ratios, which implicitly account for the record coherence in the formulation of the site amplification estimates, thus indicating divergence between the empirically estimated and theoretical transfer function caused by destructive interference phenomena (Bendat and Piersol, 1980; Safak, 1991; Steidl, 1993; Field et al., 1997). According to Safak (1997), the cross-spectral ratio is defined as the product of the spectral ratio estimate and the coherence function, and therefore, at frequencies where sinks are indeed observed in the coherence estimate, the resulting cross-spectral estimate of the transfer function is expected to deviate from the traditional spectral ratio, indicating the occurrence of destructive interference phenomena.

Despite the fact that cross-spectral ratios have been shown to potentially provide biased estimates of site amplification when evaluated in reference to a nearby rock-outcrop motion (Field et al. 1997), Safak (1997) illustrated that they 
provide probabilistically more accurate estimates than the traditional spectral ratios by proving that they represent the least-squares estimate of site amplification if the noise signals are assumed to be Gaussian random processes. Accounting for the fact that the least-squares estimate results in the minimum variance (i.e., the maximum likelihood) estimate (Kailath, 1981), the cross-spectral estimate of the transfer function corresponds to the smaller error possible at any frequency. In the ensuing, cross-spectral ratio estimates of site amplification are also evaluated for the ensemble of sites investigated, and the results are compared to the traditional spectral ratio estimates of the surface-to-borehole transfer function.

Surface-to-Rock-Outcrop Spectral Ratio (SROR). Finally, surface-to-rock-outcrop site amplification spectra were computed and compared to the traditional and cross-spectral siteresponse estimates. For the former, synthetic rock-outcrop ground-motion time histories were evaluated by deconvolution of the borehole-recorded signals to rock outcrop of the soil layer underlying the downhole instrument location at each site. Because the majority of site amplification factors are derived on the basis of strong ground-motion-surface recordings normalized by the motion recorded during the same event at a nearby rock outcrop, comparison of traditional surface-to-borehole and surface-to-rock-outcrop spectral ratios was employed here to illustrate the effects of destructive interference of downgoing waves in the foregoing site-response estimates as a function of the soil conditions.

Nonetheless, deconvolution of the borehole-recorded motions was conducted using the high-resolution soil structure that was derived on the basis of weak-motion seismogram inversion. According to the theoretical formulation, deconvolution of the surface and borehole motion would yield exactly the same rock-outcrop motion, but in the real configuration these two results are shown to be different.

This observation stems directly from the uncertainty associated with the inverted soil properties (both as a result of the idealized configuration of the forward model operator and the measurement noise) and the assumptions of vertically propagating HS waves implemented the deconvolution process, a deviation which further aggravates as the uncertainty of the soil properties, the inclination of the incident motion, and the recording signal-to-noise ratio increases.

For the purpose of this study, the borehole motion was selected to be deconvolved for the estimation of the rock-outcropping motion, because-for the most part-the profiles under investigation comprise soft near-surface sediments overlying layers with relatively high impedance contrast at the interface. As a result of this stratigraphy, the incident seismic energy is more likely to be trapped in the surficial soft layers of the profile, a fact that should minimize the potential of destructive interference phenomena occurring at the downhole instrument level, thus rendering the amplitude and frequency content of the borehole-recorded motion representative of the incident seismic energy and the resulting rock-outcrop motion. Therefore, while the amplitude of site amplification evaluated by means of the surface-to-rock-outcrop ratio is expected to differ from the corresponding amplitude of the traditional surface-toborehole ratio, the estimated resonant frequencies of the profile are expected to be identical in absence of destructive interference effects.

The anticipated deviation in site-response amplitude between the two estimators can be readily seen by considering the simple case of a homogeneous soil layer of finite and constant thickness $h$ overlying linear elastic bedrock; expressing the properties and coefficients for the soil and rock by the same letters and different subscript, denoting the train of waves with amplitude $A_{S H}$ traveling up through the underlying rock, and the amplitude of the upgoing waves through the homogeneous soil layer $\left(A_{1}\right)$ and downgoing waves in the underlying half-space $\left(A_{S H}^{\prime}\right)$, the alternative amplification functions are theoretically defined as follows, in absence of internal damping in the soil layer:

$$
\begin{gathered}
A F_{S-B}(\omega)=\frac{2 A_{1}}{A_{S H}+A_{S H}^{\prime}}=\frac{2}{e^{i p_{s} h}+e^{-i p_{s} h}}, \\
A F_{S-R O}(\omega)=\frac{2 A_{1}}{2 A_{S H}}=\frac{2}{(1+q) e^{i p_{s} h}+(1-q) e^{-i p_{s} h}},
\end{gathered}
$$

where $p=\omega / V_{s}$ is the wavenumber for vertically propagating $S$ waves of frequency $\omega$ through a medium of shear-wave velocity $V_{s}, q=\sqrt{\rho_{s} G_{s} / \rho_{R} G_{R}}$ is the admittance ratio between the soil and the rock (the inverse of the impedance ratio), $A F_{S-B}(\omega)$ is the surface-to-borehole amplification, and $A F_{S-R O}(\omega)$ is the surface-to-rock-outcrop amplification functions. Note that in the case of finite internal (material) damping in the homogeneous soil layer, the complex wavenumber is defined as $p^{*}=\omega / \sqrt{V_{s}(1+2 i \xi)}$, where $\xi=1 / 2 Q$ is the fraction of intrinsic attenuation of the medium. The amplitudes of the aforementioned functions are plotted for various levels of impedance contrast in Figure 7, which illustrates the amplitude differences anticipated to be depicted by the empirical estimates of site amplification evaluated in the ensuing.

\section{H/V Single-Station Site Amplification Estimates}

The second category of approaches for evaluating site amplification effects does not require the presence of a reference site; for a review of several non-reference-site approaches, the reader is referred to Field and Jacob (1995). One of these methods uses the spectral ratio between the $\mathrm{H} / \mathrm{V}$ spectra of the $S$-wave window for each site and is employed in the ensuing for the ensemble of stations investigated in this study using data from the 2003 Miyagi-Oki sequence. A thorough review of the $\mathrm{H} / \mathrm{V}$ non-reference-site response implementation can be found in Kudo et al. (2004). 

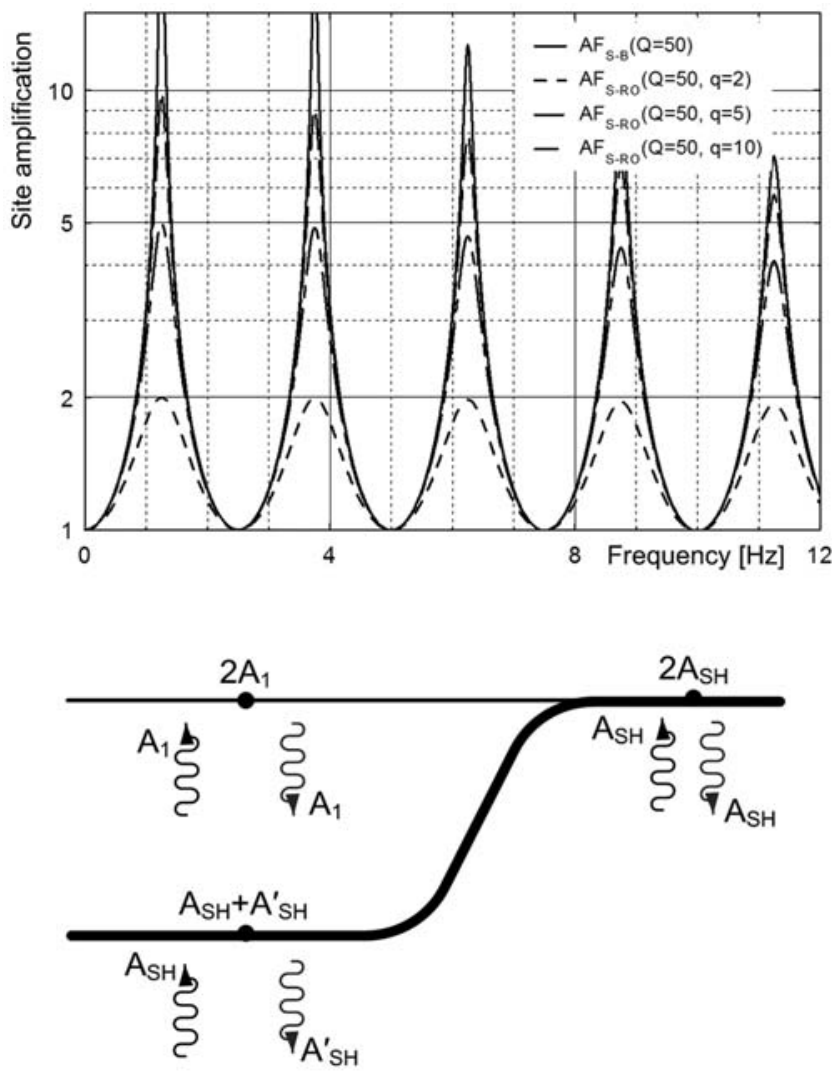

Figure 7. Influence of soil-to-rock impedance contrast to the site-response estimate for a homogeneous soil layer with $Q=50$ intrinsic attenuation factor overlying elastic undamped half-space. Comparison between theoretical transfer functions of surface-toborehole to surface-to-rock outcrop for admittance ratios $q=2$, 5 , and 10, illustrating the expected reduction in amplification amplitude estimated by the latter for relatively homogeneous formations in comparison to the corresponding surface-to-borehole observed site amplification. The surface-to-borehole amplification factor corresponds to the ratio $A F_{S-B}=2 A_{1} /\left(A_{S H}+A_{S H}^{\prime}\right)$, while the surface-to-rock-outcrop amplification factor corresponds to the ratio $A F_{S-R O}=2 A_{1} / 2 A_{S H}$.

Despite the large number of studies on the accuracy of $\mathrm{H} / \mathrm{V}$ site amplification estimates (e.g., Tokimatsu et al., 1998; Lachet and Bard, 1994; Arai and Tokimatsu, 2000), there still exists debate on the range of applicability of this method. Studies of the H/V spectral ratio (e.g., Lachet and Bard, 1994; Field and Jacob, 1995; Field, 1996; Lachet et al., 1996) show that estimates of the frequency of the predominant peak are similar to that obtained with traditional spectral ratios; however, the absolute level of site amplification does not correlate with the amplification obtained from the more traditional methods. Discrepancies among the aforementioned studies are primarily attributed to the fact that $\mathrm{H} / \mathrm{V}$ ratios are strongly affected by scattered phases and surface waves propagating within the shallow deposits and contributing to the spectral amplitudes of both the horizontal and vertical components (e.g., Riepl et al., 1998). As a result of these complications and the influence of incidence angle on the percent of mode conversion, the $\mathrm{H} / \mathrm{V}$ ratio is generally found to depict the primary resonance peak but not to accurately determine amplification levels (e.g., Bonilla et al., 1997; Riepl et al., 1998; Parolai and Richwalski, 2004).

Comparison of Alternative Techniques for the 2003 Miyagi-Oki Aftershock Sequence

Initially, site amplification estimates described in the previous sections are depicted and compared at three profiles, each representative of the site classes B, C, and D investigated-in Figure 8c. For each profile, the empirical surface-to-borehole transfer functions (spectral ratios) are averaged across the ensemble of recorded weak-motion events, and both the mean and \pm 1 standard deviation estimates are plotted as a function of frequency. Note that site MYGH05 (class D) is characterized by a relatively constant velocity variation with depth, site IWTH05 (class C) is characterized by an strongly increasing (from 0.1 to $2.8 \mathrm{~km} / \mathrm{sec}$ ) shear-wave velocity profile between 0 - and $70-\mathrm{m}$ depth, and site IWTH23 (class B) has a shallow soft $(0.25 \mathrm{~km} / \mathrm{sec})$ layer in the near surface overlying a relatively homogeneous stiff formation with strong impedance contrast at approximately 10-m depth. Therefore, while profile MYGH05 is anticipated to allow destructive interference phenomena to materialize, the structure of profiles IWTH05 and IWTH23 is expected to result in trapping of wavelengths of equal or shorter length to the near-surface soft layers, strong amplification of the corresponding high-frequency components of incident motion, and reduced potential of observed destructive interference at the borehole level.

The average coherence estimate is also depicted for each geotechnical array, whereas the frequencies at which destructive interference is expected to occur based on the equivalent homogeneous medium approach (Steidl et al. 1996) are estimated to be $0.56,4.35$, and $4.52 \mathrm{~Hz}$ for sites MYGH05 (class D), IWTH05 (class C), and IWTH23 (class B), respectively. As can be readily seen, the effect of destructive interference is clear for the site MYGH05, where the theoretically predicted frequency of its occurrence coincides with a clear depression in the coherence estimate. By contrast, destructive interference is not observed for the stiffer sites (namely, IWTH05 and IWTH23) at the theoretically estimated value. In particular, the following applies:

1. For site IWTH05, the spectral ratio peak at $3.5 \mathrm{~Hz}$ corresponds to a coherence local minimum, implying that destructive interference does indeed occur at this frequency, yet the phenomenon is not adequately described by the equivalent homogeneous medium (Fig. 8d).

2. For site IWTH23, destructive interference phenomena are very subtle, a fact that is attributed to the near-surface strong impedance contrast of the profile (i.e., in between the surface and borehole instruments), where the upgoing (incident) energy is trapped and subsequently absorbed in the course of its resulting multiple reverberations (Fig. 8d). The strong near-surface impedance contrast 

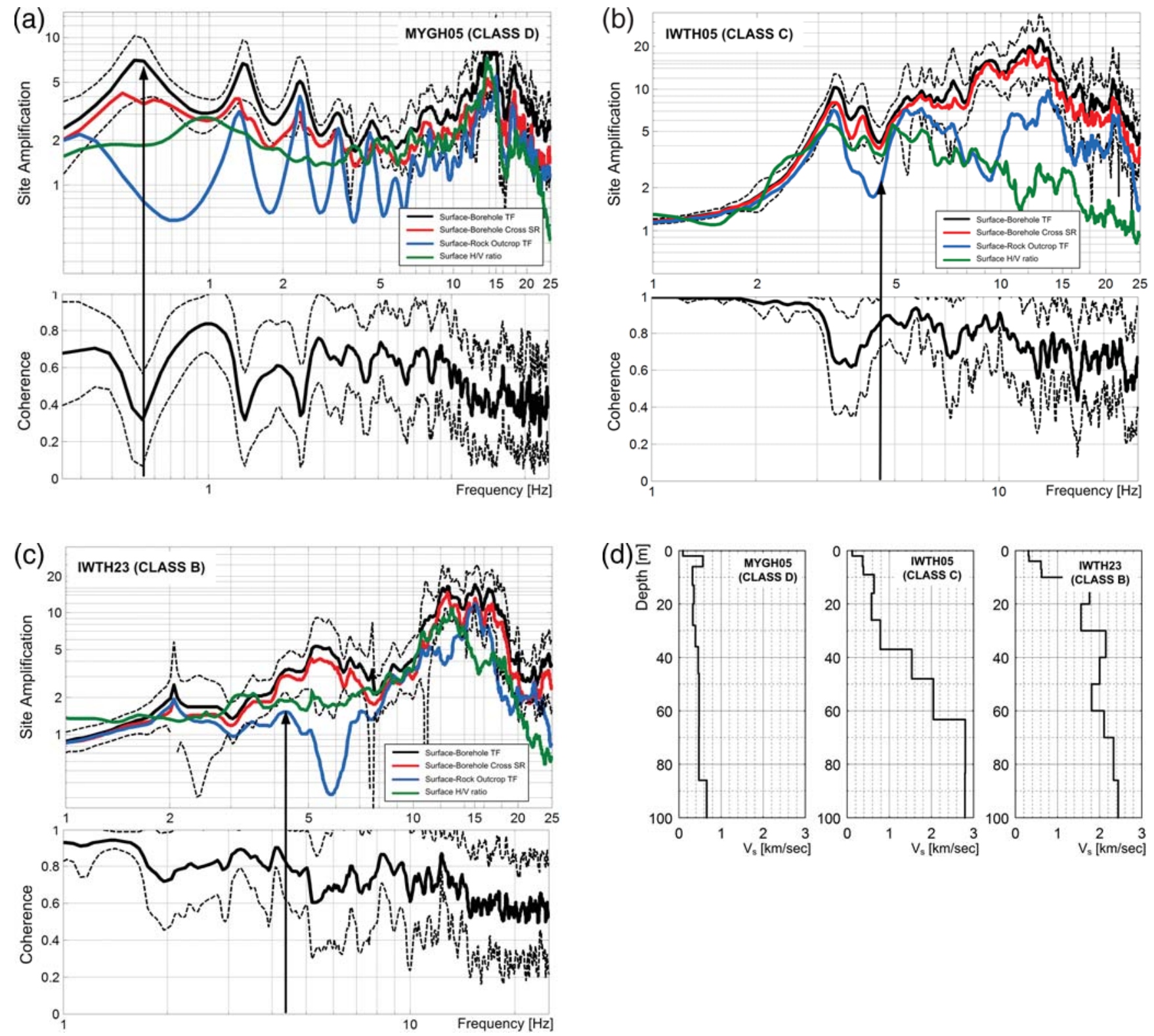

Figure 8. (a)-(c) Averaged site amplification estimates compared in this study for three representative sites of the soil conditions investigated (classes B,C, and D), namely, empirical SSR, c-SSR, and H/V ratios, and surface-to-rock-outcrop site amplifications (the latter deconvolved from the borehole motion). Also shown are the corresponding average magnitude-squared coherence estimates of the surface-toborehole observations. The arrows indicate the frequencies where theory predicts depression of the coherence function corresponding to destructive interference between upgoing and downgoing waves at the borehole instrument level, assuming a homogeneous interstation material. (d) Shear-wave velocity profiles with depth for the three sites compared here, as estimated by means of the global-local optimization algorithm using multiple weak-motion records at each site.

that prevents destructive interference effects from materializing at the borehole level, however, results in the observed strong site amplification of high-frequency components of ground motion $(10-20 \mathrm{~Hz})$, a fact that conflicts the classification of this profile as a "reference site" based on the averaged near-surface weighted average shear-wave velocity.

Successively, the methods for estimation of site amplification factors are compared by averaging the spectral ratio for each method at each station over seven center frequencies following Bonilla et al. (1997). A bandwidth of $\pm 0.25 \mathrm{~Hz}$ was used for the center frequency at 0.75 and $1.0 \mathrm{~Hz}, \pm 0.5$ for the center frequency at 1.5 and $2.0 \mathrm{~Hz}$, and \pm 1.0 for the remaining center frequencies at 3.0, 4.0, and $6.0 \mathrm{~Hz}$. Then the averaged amplifications at each center frequency were plotted for the different methods.

Figure 9 summarizes a comparison of the results from all site amplification methods employed; in Figure 9a, the solid 
lines represent 1:1 correspondence between methods, while the dashed lines show a factor of 2 of difference between methods. The ensemble of methods are first compared in Figure 9a, where the horizontal axis corresponds to the amplification estimated via the surface-to-borehole traditional spectral ratio, and the vertical axis represents the siteresponse amplitude computed via the surface-to-borehole cross-spectral ratio, surface $\mathrm{H} / \mathrm{V}$ ratio, and surface-to-rockoutcrop spectral ratio at the corresponding frequency range. As can be readily seen, destructive interference phenomena result in systematic overestimation of the site response by means of the surface-to-borehole transfer function, with the exception of the single-station $\mathrm{H} / \mathrm{V}$ site amplification estimates in the low-frequency range.

The estimates of observed cSSR and SROR amplification, however, are shown to be less scattered around the 1:1 correspondence line, and comparison of the averaged values is next depicted in Figure 9b. As documented by Safak (1997), estimation of site amplification spectra by means of surface and borehole records through cross-spectral ratios, which accounts for the surface-to-borehole record coherence estimate thus removing the effects of destructive interference, is indeed a better estimator of the target surface-to- rock-outcrop site response. It should be noted, however, that the latter is here estimated by deconvolution of the borehole record based on the inverse profile computed at the station. Therefore, inasmuch as the waveform inversion algorithm allowed for high-resolution velocity, attenuation, and density profiles to be estimated, the deconvolution process introduces uncertainty in the resulting site amplification estimator compared to the observed quantities. In absence, however, of a true reference site (i.e., a site with unit site amplification) in the vicinity of the stations under consideration, the deconvolution process described previously, which is based on properties that optimize the cross correlation between predicted and observed surface waveforms, is considered to be a good approximation to the hypothetical observed site amplification.

Finally, site amplification spectra obtained by means of the four methods described in the previous paragraphs are shown in Figure 10. The spectra here are averaged across the ensemble of records obtained within each of the three site classes of soil conditions investigated (classes B, C, and $\mathrm{D}$ ), while for each method and site class, the average distribution is compared to the observed surface-to-borehole site amplification estimate. As shown in Figure 9a for the
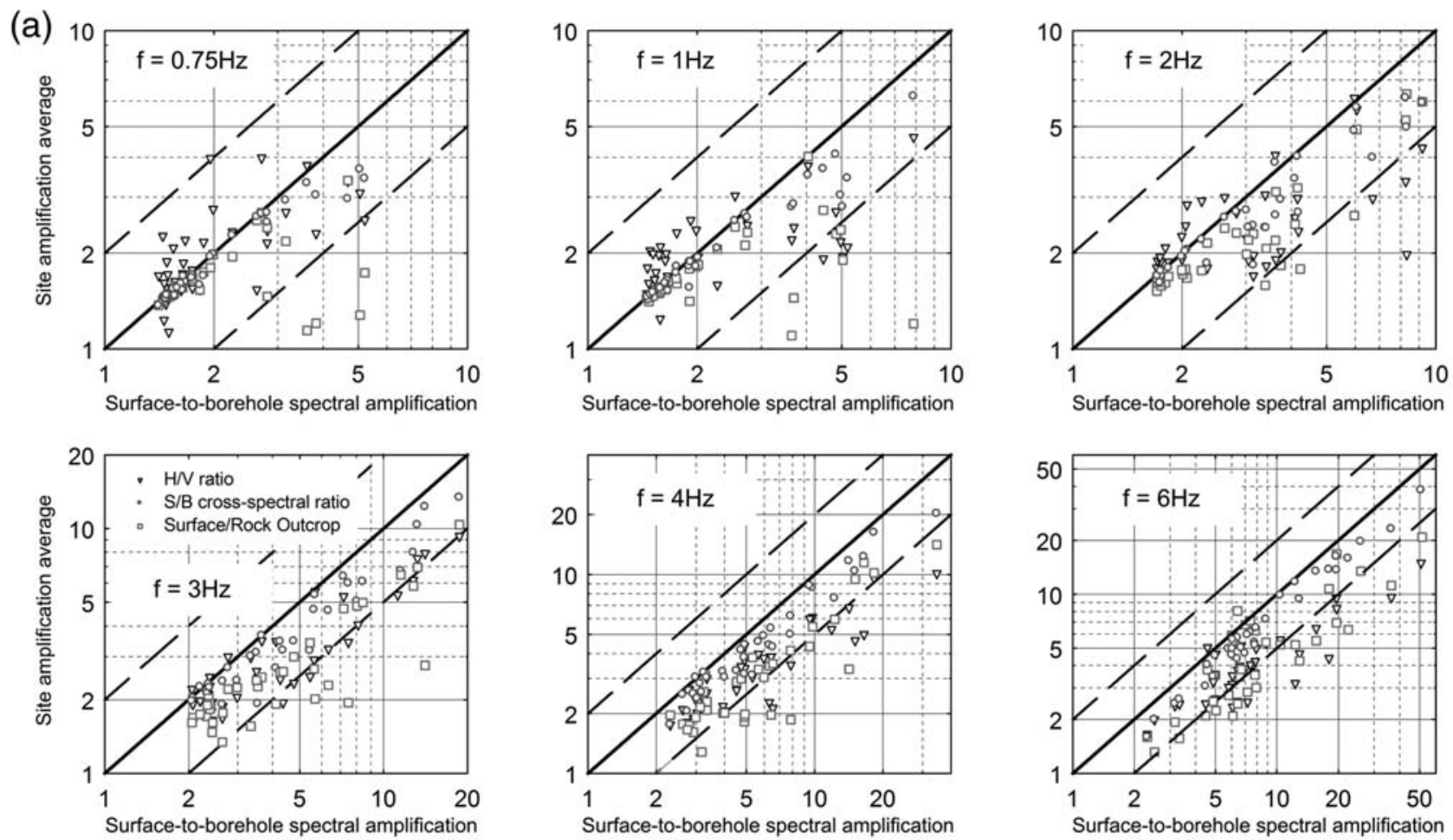

Figure 9. (a) Comparison between the alternative site amplification estimates, averaged across several narrow frequency windows with central frequency indicated on each figure (i.e., $0.75,1,2,3,4$, and $6 \mathrm{~Hz}$ ). The horizontal axis corresponds to the amplification estimated via the surface-to-borehole recorded ground motion, while the vertical axis represents the corresponding amplification computed via the surfaceto-borehole cross-spectral ratio, surface $\mathrm{H} / \mathrm{V}$ ratio, and surface-to-rock-outcrop spectral ratio; the black line represents 1:1 correlation of the predicted amplification between the alternative methods, while the dashed lines correspond to a factor of 2 range in the amplification predictions. (b) Same as (a), but limited to the comparison between surface-to-borehole cross-spectral amplification and surface-to-rock-outcrop amplification.

(Continued) 

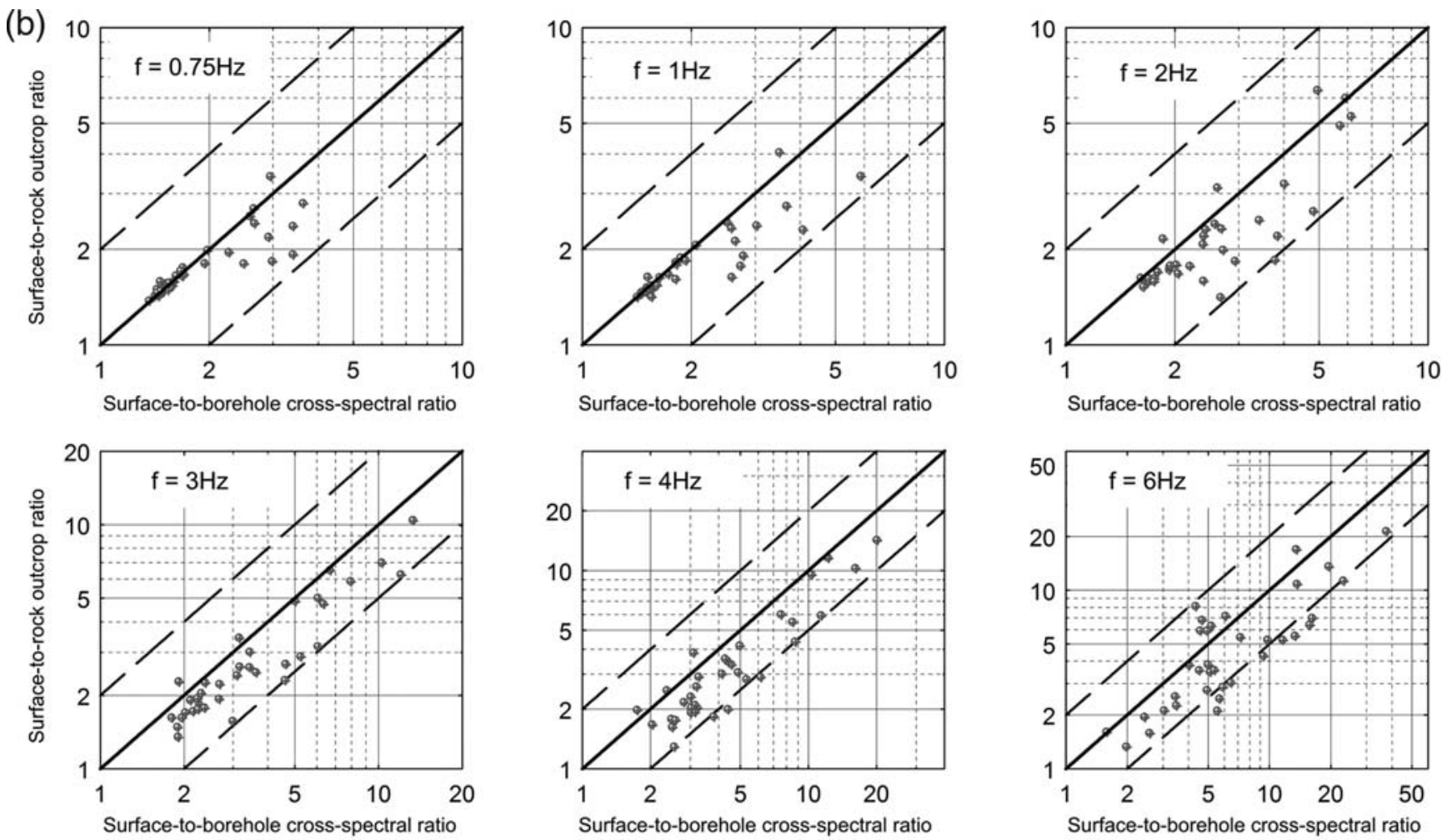

Figure 9. Continued.

averaged site amplification factors, surface-to-borehole spectra systematically overestimate the amplification potential for all site conditions examined, while the discrepancy between the average surface-to-borehole observed and hypothetical surface-to-rock-outcrop amplification is reduced as the nearsurface stiffness reduces.

This effect is most probably attributed to the effects of destructive interference that are less pronounced for softer site conditions (i.e., class D in this study) with potentially stronger impedance contrast to the underlying stiffer layers (provided that this interface is encountered between the surface and borehole instruments). The resulting reduced amplitude of downgoing waves in turn reduces the potential of spurious peaks and associated amplitude increase in the surface-to-borehole spectral ratio. It should be noted, however, that while this trend is here observed for the averaged spectra of site amplification and the site conditions investigated, there might exist site-specific conditions as shown in Figure $8 \mathrm{c}$ in which the site classification of the soil profile does not reflect the average velocity distribution, namely, a class B site is characterized by a very soft layer on the surface minimizing the amplitude of downgoing waves for wavelengths equal or shorter than the layer thickness.

Similar observations have been also reported by Steidl et al. (1996) and Bonilla et al. (1997) for the site-specific conditions at Garner Valley, California, and they highlight the need for site classification criteria to be reevaluated and refined accordingly. Considering that in order to achieve a complete description of the site amplification potential (and associated nonlinearity susceptibility under strong ground motion), the near-surface averaged impedance categorization of the profile should be complemented by a quantitative description of the correspondence between incident motion frequency content and theoretical site amplification, thus illustrating the potential of the local site conditions to amplify (or deamplify) the incoming seismic energy.

\section{Site Amplification Factors via Seismogram Inversion}

\section{Amplification Factors in Currently Employed Attenuation Relations}

Amplification factors in general describe the ratio of an observed intensity measure to a reference value of the same quantity, and in particular for the evaluation of site amplification factors from ground-motion recordings; this process typically involves comparison of intensity measure spectra from sites with various geologic conditions to the corresponding spectra evaluated at reference (usually firm rock) sites with appropriate corrections for distance variations between the sites (Stewart et al., 2003). 

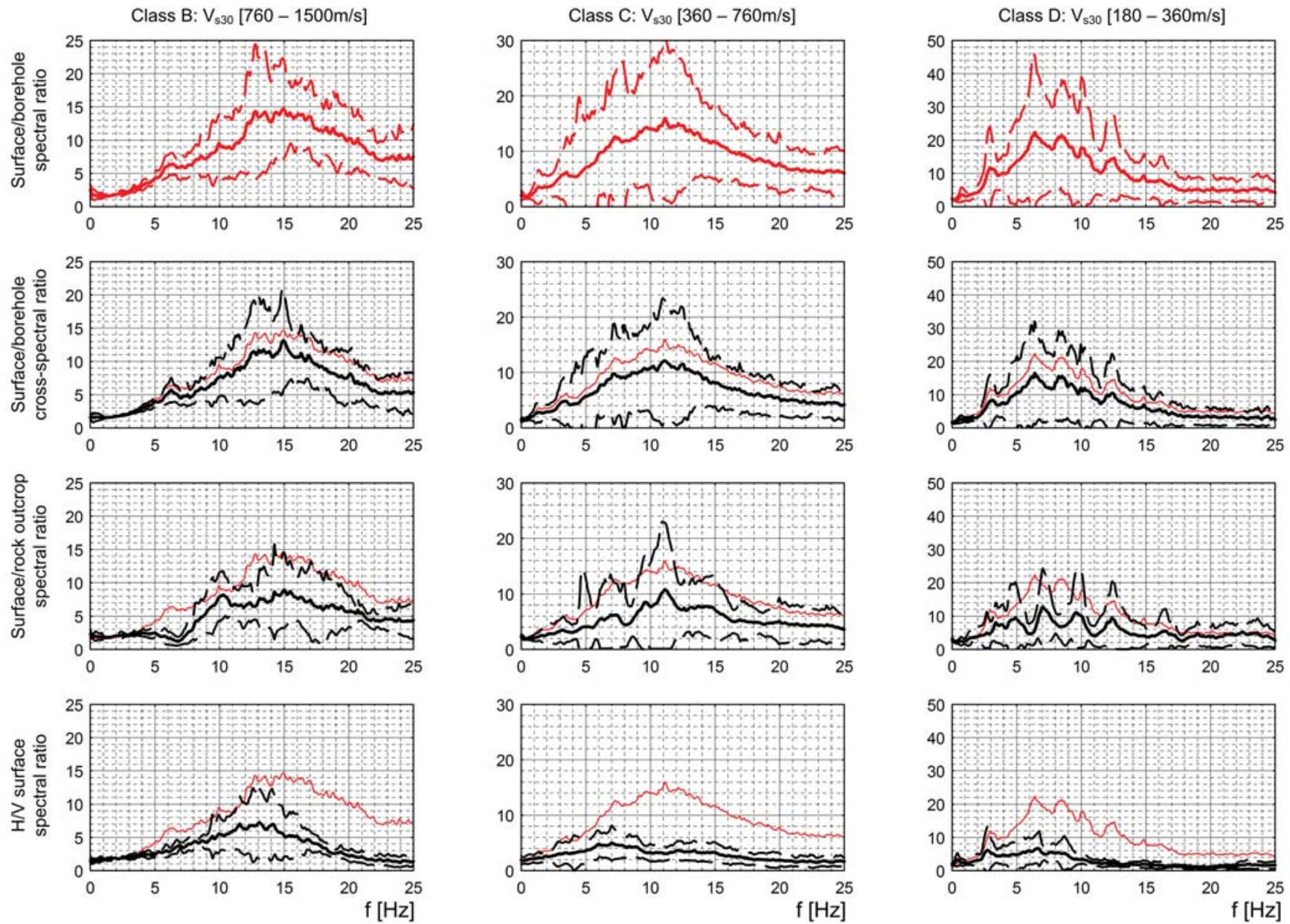

Figure 10. Comparison between average \pm 1 standard deviation intraclass amplification spectra for the different site amplification estimates and the three NEHRP site classes (B, C, and D) of this study.

Therefore, the most commonly employed technique to incorporate site effects into a ground-motion estimation relation is the use of multiplicative factors between ground motion at the type of site of interest and the corresponding motion at the so-called reference site (Douglas, 2003). In the National Earthquake Hazards Reduction Program NEHRP Recommended Provisions for Seismic Regulations for New Buildings and Other Structures, Part 1: Provisions and Part 2: Commentary (BSSC, 2001) for example, source and path effects are accounted for by means of s (PSHA employed for a particular site condition (Frankel et al., 2000), while the effects on spectral ordinates of site conditions that deviate from the reference velocity $\left(V_{s 30}\right)$ are accounted for with site factors that are a function of site category and the amplitude of shaking for the reference-site condition (Dobry et al., 2000; Stewart et al., 2003). It should be also noted that the currently employed reference condition is defined at the interface between the NEHRP B and C site classes, namely sites characterized by $V_{s 30}=760 \mathrm{~m} / \mathrm{sec}$, and is also referred to as the $\mathrm{B}-\mathrm{C}$ boundary.
As can be readily seen, the attenuation relationships used to evaluate the probabilistic distribution of a given spectral ordinate at a site should apply only for a particular site condition (i.e., the average site condition at the stations that recorded the data used to derive the attenuation relation), and therefore their results should also apply only for the average site condition in the attenuation model. The attenuation relations, however, used to develop the PSHA maps for $T>0$ spectral ordinates in the 2000 NEHRP provisions are the Boore and Joyner (1997) and Sadigh et al. (1997) relationships; and despite the fact that the Boore and Joyner relation may be directly implemented for the B-C boundary because site conditions are parameterized with respect to $V_{s 30}$, the average velocity of reference sites for the Boore and Joyner (1997) relationship is approximately $620 \mathrm{~m} / \mathrm{sec}$ (Silva et al., 1997), while for the Sadigh et al. (1997) it is approximately $520 \mathrm{~m} / \mathrm{sec}$. Even further, while the hazard analyses used for implementation in the 2003 maps were expanded to include the Abrahamson and Silva (1997) and Campbell and Bozorgnia (2003) attenuation relations, these relations have been 
also developed for site categories inconsistent with the NEHRP B-C boundary (Choi and Stewart, 2005).

Currently employed NEHRP site factors are based on both empirical data and ground response analyses conducted by Dobry et al. (2000). The empirical studies had been performed by Borcherdt (1994), Borcherdt and Glassmoyer (1994), and Joyner et al. (1994) using strong-motion data recorded in the San Francisco Bay area during the 1989 Loma Prieta earthquake and have led to amplification factors $\left(F_{a}\right.$ and $F_{v}$ ) applicable for relatively weak levels of shaking (peak horizontal acceleration for reference-site conditions and peak horizontal acceleration at the reference site on the order of $\approx 0.1 \mathrm{~g}$ ). These amplification factors were derived using a so-called reference-site approach in which the amplification is defined as the ratio of Fourier spectral ordinates of motions recorded on soil to those recorded on nearby reference rock sites. In particular, the specific factors given in the provisions are $F_{a}$, which is defined over a low-period range $(0.1-0.5 \mathrm{sec})$, and $F_{v}$, which is defined over a midperiod range $0.4-2.0 \mathrm{sec}$ ). The ground-motion parameters for the reference-site condition that are used in conjunction with site factors are $T=0.2 \mathrm{sec}$ spectral acceleration for $F_{a}$ (denoted $S_{s}$ ) and spectral acceleration at $T=$ $1.0 \mathrm{sec}$ for $F_{v}$ (denoted $S_{l}$ ) (Fig. 11).

Borcherdt (2002) investigated amplification levels within NEHRP categories using recordings from the 1994 Northridge earthquake, which were found to match very well with the NEHRP amplification factors from the Loma Prieta records, both at small periods $\left(F_{a}\right)$ and at longer periods $\left(F_{v}\right)$. Harmsen (1997) evaluated amplification factors within NEHRP categories using data from multiple southern California earthquakes normalized relative to a single reference rock site (Caltech Seismic Lab). Field (2000) evaluated amplification factors as a direct function of $V_{s 30}$ using a nonreference-site approach in which amplification factors were derived as a term within a southern California attenuation relationship. Steidl (2000) also used a non-reference-site approach, evaluating site factors as a function of $V_{s 30}$ using residuals from the Sadigh et al. (1997) attenuation relationship for rock sites (similar to the Sadigh et al., 1997, relation). The amplification factors from the Harmsen and Field studies are independent of reference-site peak horizontal acceleration $\left(\mathrm{PHA}_{r}\right)$. Joyner and Boore (2000) developed amplification factors within NEHRP categories using a procedure similar to that of Field (2000) described earlier in this article, although the short-period factors are expressed as a function of reference motion amplitude. Stewart et al. (2003) developed nonlinear amplification factors within NEHRP categories relative to the Abrahamson and Silva (1997) attenuation relationship. Recently, Choi and Stewart (2005) derived amplification factors based on 1828 recordings from 154 earthquakes, using recordings from worldwide shallow crustal earthquakes near active plate margins and excluding subduction and interplate events. By contrast to all the of the studies discussed in this article, the latter amplification factors were derived as continuous functions of both $\mathrm{PHA}_{r}$ and
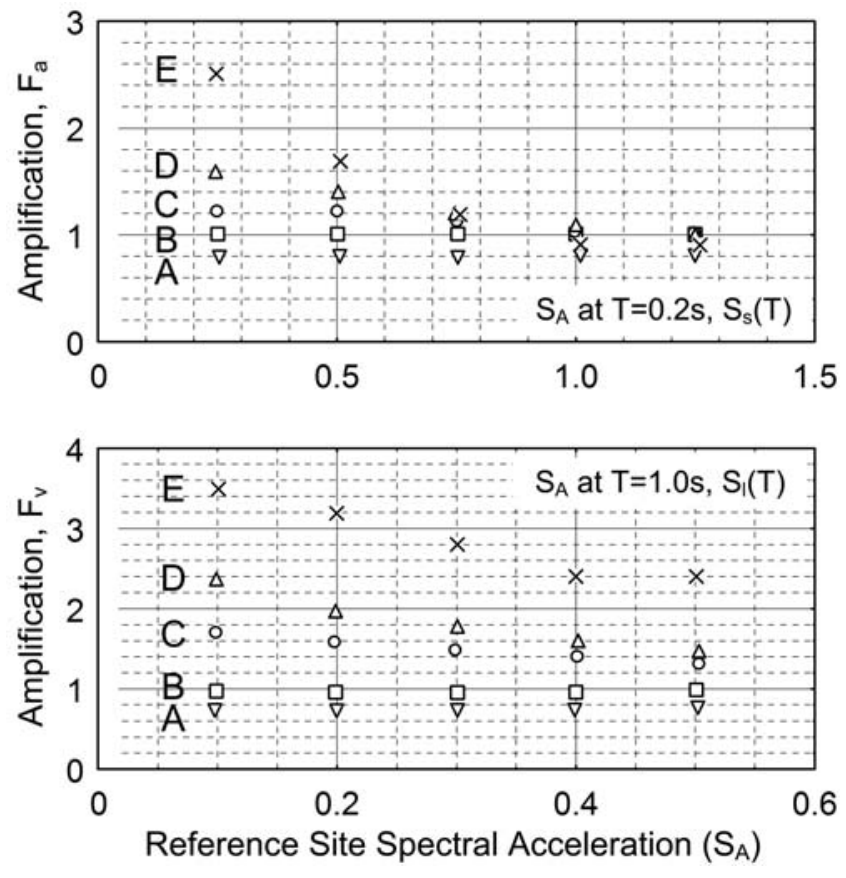

Figure 11. Site amplification factors suggested by the NEHRP provisions (BSSC, 2001): $F_{a}$ is defined over a low-period range ( $T=0.1-0.5 \mathrm{sec})$, and $F_{v}$ is defined over a midperiod range $(T=0.4-2.0 \mathrm{sec})$. These site factors are used in conjunction with the ground-motion parameters for the reference-site condition, namely the SA at $T=0.2 \mathrm{sec}$ for $F_{a}$ denoted $S_{s}$, and SA at $T=$ $1.0 \mathrm{sec}$ for $F_{v}$ denoted $S_{l}$ (modified from Choi and Stewart, 2005).

$V_{s 30}$. In the ensuing, amplification factors computed in this study using the 2003 Miyagi-Oki sequence will be compared to the aforementioned studies.

\section{Site Amplification Factors from the Miyagi-Oki Aftershock Sequence}

The most computational intensive method for including local site effects within an ground-motion estimation study is to convert all the recorded time histories from sites with a variety of properties to time histories that would have been recorded on a site with given properties. As an example, this procedure was adopted by Annaka and Nozawa (1988), who use 1D propagation theory to transform records from sites with $V_{s}<300 \mathrm{~m} / \mathrm{sec}$ to records from sites with $V_{s}>$ $300 \mathrm{~m} / \mathrm{sec}$ and Kawanoa et al. (2000), who eliminated the effects of the uppermost layers of ground under a station to get a record which comes from a site with $0.5<$ $V_{s}<2.7 \mathrm{~km} / \mathrm{sec}$. Despite the fact that the altered recorded time history could lead to increased uncertainty, the use of seismic data from geotechnical arrays in conjunction with site-specific properties developed on the basis of seismogram inversion at the stations of interest is considered to minimize the uncertainty arising from the incident motion description and the site-response characterization in that process. Based on this assumption, weak-motion data recorded by the 37 stations under investigation are used in the ensuing to evaluate 
site amplification factors in the region of interest with respect to the B-C boundary site conditions $\left(V_{s 30}=\right.$ $760 \mathrm{~m} / \mathrm{sec}$ ), namely, the reference condition that the NEHRP PSHA maps are developed to apply for (i.e., the site conditions for which the attenuation relations used in the hazard analyses should also be appropriate).

In the ensuing, amplification factors are derived from weak-motion recordings characterized by a maximum PHAPHA $_{r}$ of approximately $0.1 \mathrm{~g}$. For this purpose, seismogram inversion results are being used in conjunction with weak-motion recordings from the 2003 Miyagi-Oki aftershock sequence, and ground surface and downhole records are initially deconvolved to ground surface of a typical B-C boundary reference profile following Hartzell et al. (2002) under the assumption of linear site response that is considered to be valid given the amplitude of weak ground motions investigated in this study. It should be noted here that if indeed the forward model operator were the precise mathematical representation of the site-response physical mechanism, the global optimum solution of the inversion process would have yielded the exact variation of soil properties at the site of interest, and under the assumption of vertically propagating upgoing and downgoing waves between the surface and borehole receivers, deconvolution of both records should yield identical predicted $\mathrm{B}-\mathrm{C}$ boundary ground motion.

Nonetheless, epistemic and aleatory uncertaintiesboth in the inversion and the forward simulation processresult in the observed diversity between the aforementioned reference-site estimates, and for this purpose the average response spectral ratios are here used for the development of weak-motion site amplification versus $V_{s 30}$ regression. Similarly to the surface-to-rock-outcrop site amplification spectra, empirical site amplification factors are next computed as shown in Figure 6, namely as the average response spectral ratio of the surface $\left(A_{1}\right)$ to the reference-site ground motion, the latter derived via deconvolution of the surface $\left(A_{1}\right)$ or the borehole $\left(A_{2}\right)$ recorded motion correspondingly.

The ensemble of response spectral amplification ratios to the reference-site conditions, categorized per site class are first shown in Figure 12. As mentioned previously in this section, despite the overall stiff-site conditions prevailing in the area of interest, relatively thin layers of soft sedimentary deposits $(5-15 \mathrm{~m})$ are commonly encountered in the near surface, a stiffness distribution characteristic of all three site classes investigated in this study. As a result, the following are true:

1. The ensemble of site amplification spectral ratios for class B sites depicted in Figure 12a is shown to have the anticipated reference-site (i.e., unity) amplification potential in the period range $(0.15-2 \mathrm{sec})$, while the distinct high-frequency amplification of average amplitude on the order of 4 observed in the $(0.05-0.1-\mathrm{sec})$ region is clearly reflecting the trapping of short-wavelength components of the incident motion in the near surface of the profile.
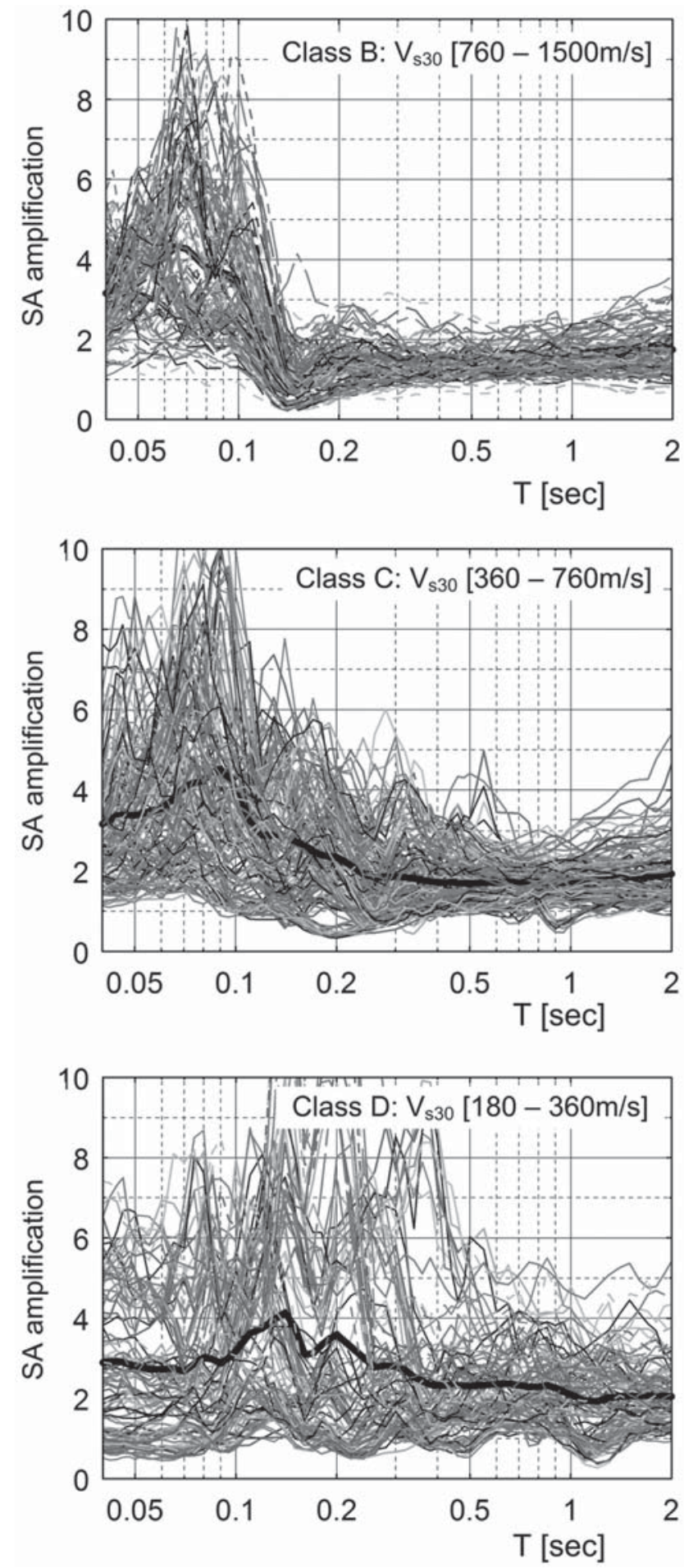

Figure 12. Site amplification response spectral ratios with respect to the NEHRP B-C boundary reference-site conditions $\left(V_{s 30}=760 \mathrm{~m} / \mathrm{sec}\right)$ for the ensemble of weak-motion recordings investigated in this study, categorized and averaged per site class based on the NEHRP site classification system.

2. The average spectral amplification ordinates estimated for class $\mathrm{C}$ site conditions depicted in Figure 12b are shown an average of 2 amplification ratio in the period 
range $(0.2-2 \mathrm{sec})$, while the lower period region is here also characterized by a larger amplification amplitude on the order of 4 in a wider region than the one observed for the stiffer site class B conditions described in this article, namely $(0.05-0.2 \mathrm{sec})$ corresponding to thicker and/or softer material in the near surface.

3. Results obtained for the softer site conditions investigated in this study are finally shown in Figure 12c. The distribution of amplification spectra is shown, however, to be scattered both in amplitude and frequency, corresponding to the variability of shear-wave velocity distribution of profiles within this site class and resulting in a smooth average spectral amplification on the order of 3 in the short period $(0.05-2 \mathrm{sec})$ and of 2 in the long period $(0.2-2$-sec) regions of the spectrum. This result also highlights the emerging need for refinement of the currently employed site classification system, opting to reduce the associated amplification potential variability reflected in seismic design code provisions and probabilistic seismic hazard analyses.

Successively, amplification factors defined as the averaged response spectral ratio of ground surface records to the B-C boundary estimated ground motion at short $\left(T_{s}=\right.$ $0.3 \mathrm{sec})$ and long $\left(T_{l}=1.0 \mathrm{sec}\right)$ periods as a function of the weighted average top $30-\mathrm{m}$ shear-wave velocity $\left(V_{s 30}\right)$ are compared in Figure 13a to existing amplification functions from previous studies, namely to Choi and Stewart (2005) evaluated at $\mathrm{PHA}_{r}=0.1 \mathrm{~g}$ (Borcherdt and Glassmoyer [1994]; Harmsen [1997]; Field [2000]; Steidl [2000]; and Stewart et al. [2003]) as well as the currently employed amplification functions for weak ground motion in the NEHRP provisions (BSSC, 2001). As can be seen, data evaluated in this study are shown to exceed the predicted amplification potential for class $\mathrm{C}$ and class $\mathrm{D}$ site conditions in the short-period region $(T=0.3 \mathrm{sec})$, a fact that reflects the particularity of site conditions in the area interest where soft near-surface soil layers overlying formations with a strong interface impedance contrast aggravate the amplification potential of high-frequency components of incident ground motion. The variability of soil profiles within each site class is also reflected in the long period region of the amplification spectrum $(T=1 \mathrm{sec})$. Nonetheless, the maximum amplification evaluated in this study may be approximated by the Harmsen (1997) amplification function for class D and class B conditions, while the data from class $\mathrm{C}$ sites appear to be largely scattered with predicted amplification from approximately 0.8 to 3 .

Comparison with previous site amplification studies evaluated on the basis of strong-motion records and siteresponse models in the low $\mathrm{PHA}_{r}$ range is next illustrated in Figure 13b; comparison is depicted between the amplification factors estimated through the 2003 Miyagi-Oki aftershock sequence at 37 stations evaluated for $V_{s 30}=$ $760 \mathrm{~m} / \mathrm{sec}$ reference-site conditions via deconvolution, the Borcherdt (2002) amplification factors, which apply for a slightly stiffer reference-site condition of $V_{s 30}=850 \mathrm{~m} /$ $\mathrm{sec}$, the amplification factors for NEHRP categories by Stewart et al. (2003), which have been adjusted to a reference-site condition of $760 \mathrm{~m} / \mathrm{sec}$ using a bias adjustment factor, the Joyner and Boore (2000) amplification factors for reference condition $V_{s 30}=760 \mathrm{~m} / \mathrm{sec}$, and the Choi and Stewart (2005) site amplification factors evaluated for the baseline amplitude ground motion (namely $\mathrm{PHA}_{r} \approx 0.1 \mathrm{~g}$ ) and adjusted to $V_{s 30}=760 \mathrm{~m} / \mathrm{sec}$.

Ensuring compatibility among the observations from this work and past studies, comparison among the alternative models is here conducted following Choi and Stewart (2005), who compared previously developed attenuation relations to their models after removing the bias associated with inconsistent reference-site conditions. In particular, as noted by Choi and Stewart (2005), the reference-site conditions $\left(V_{\text {ref }}\right)$ values for the alternative models span a wide range, namely from $V_{s 30}=520 \mathrm{~m} / \mathrm{sec}$ (Silva et al. 1997) to $V_{s 30}=850 \mathrm{~m} / \mathrm{sec}$ (Borcherdt, 2002). This variability in reference-site conditions among the various models implies variability of the response characteristics of the reference-site configuration, which-despite the absence of nonlinearity for the low level of ground motion investigated hereincauses inconsistent suppression or enhancement of certain harmonics in the site amplification factor evaluation among the different models compared. Choi and Stewart (2005) accounted for this inconsistency of reference-site conditions in their attenuation relations by introducing the following power law equation to evaluate the target regression fit to the ensemble of weak-motion data:

$$
F(T)=\left(V_{s 30} / V_{\text {ref }}\right)^{c}=\left(V_{s 30} / 760\right)^{c},
$$

where $V_{s 30}$ is the measured and $V_{\text {ref }}$ is the reference site (the $\mathrm{B}-\mathrm{C}$ boundary conditions) weighted average shear-wave velocity at the upper $30 \mathrm{~m}$ of the profile, and $c$ is the power law's regression coefficient; it should be noted that among the relations proposed by Choi and Stewart (2005), comparison is shown in the ensuing with site amplification factors developed for weak ground-motion recordings. Note that $\mathrm{PHA}_{r}$ values estimated in this study span the range from 0.001 to $0.1 \mathrm{~g}$, a fact that stems directly from the selection process of the seismogram recordings that was based on a maximum amplitude criterion to ensure the validity of linear elastic soil response in the forward model operator of the optimization algorithm employed.

As can be readily seen in Figure 13b, both short- and long-period amplification factors are shown to be consistent with previous studies for class B site conditions; the estimated spectral amplification values are scattered around unity, a fact that illustrates the anticipated reference-site response of profiles in this category, while spanning amplitudes from 0.5 to 2. Amplification factors are shown to be substantially more scattered for class C conditionsespecially in the short-period region reflecting amplification of short wavelengths trapped in the near-surficial layers of 

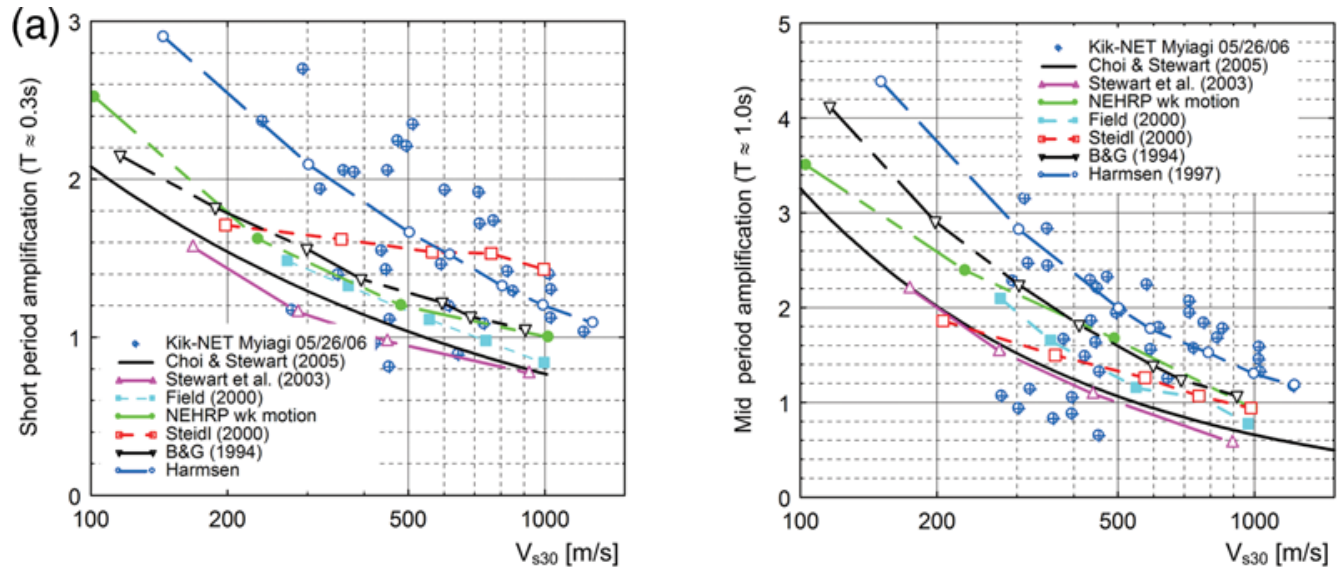

(b)
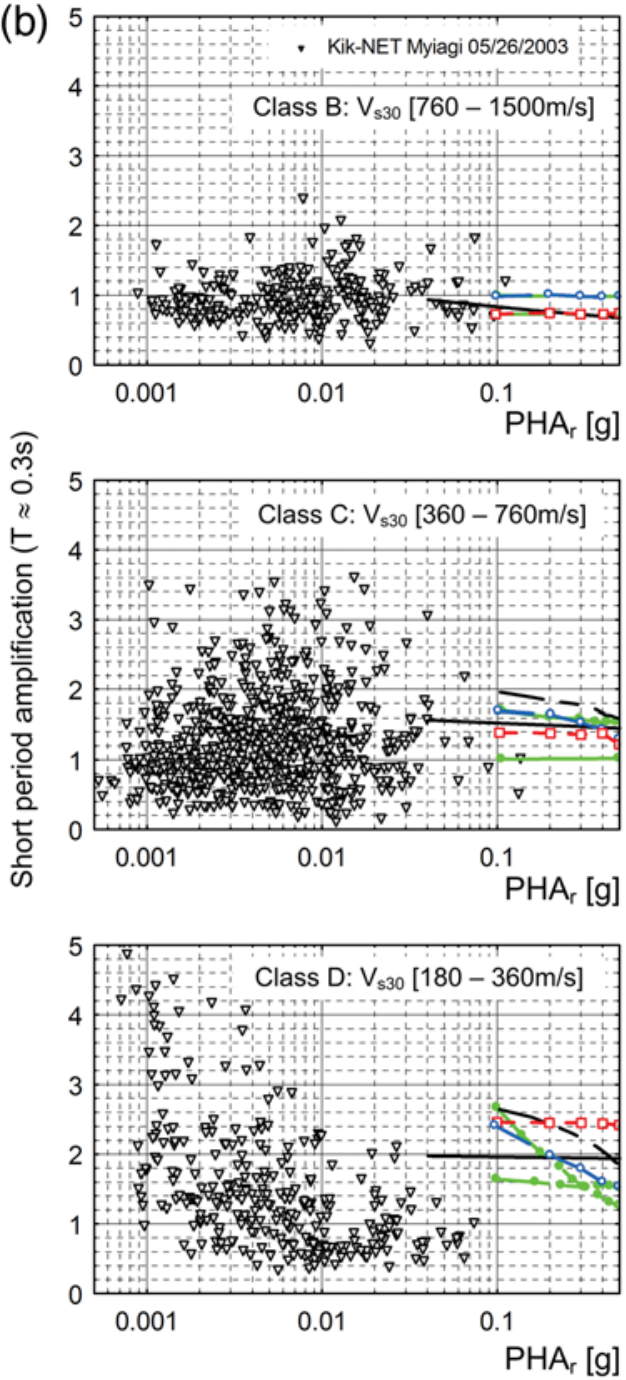
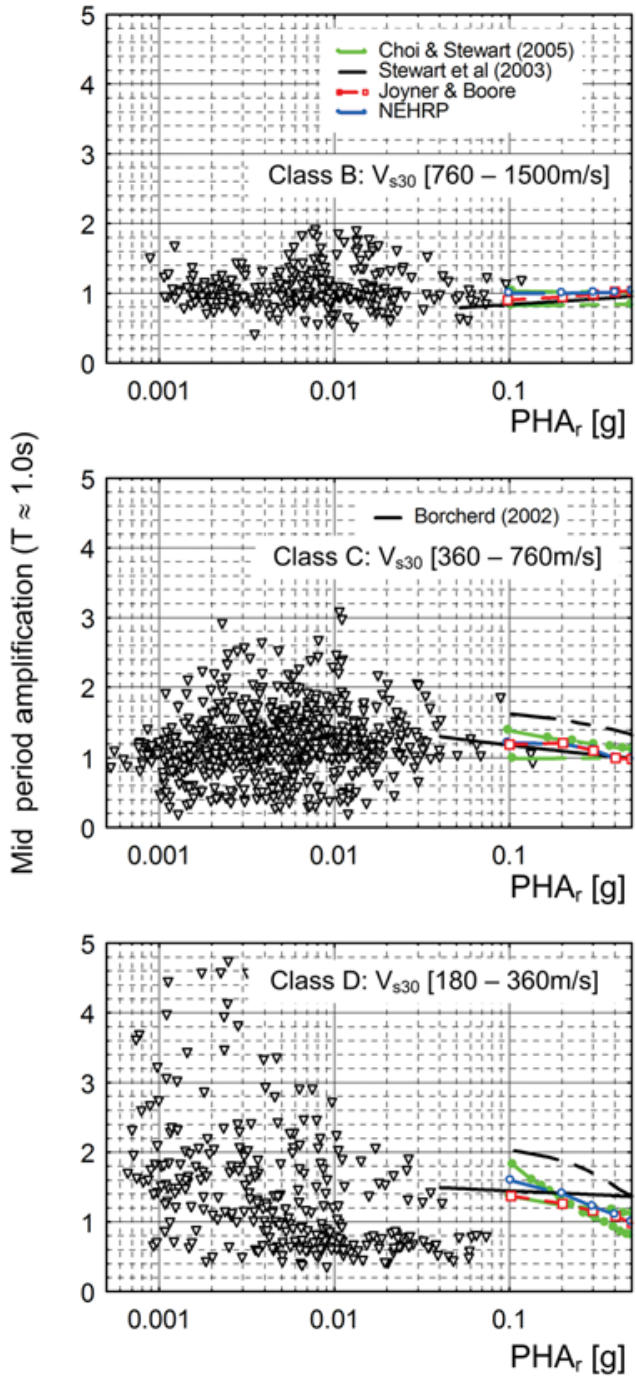

Figure 13. (a) Comparison of the dependence of short-period $(T=0.3 \mathrm{sec})$ and midperiod $(T=1.0 \mathrm{sec})$ amplification values on $V_{s 30}$ computed in this study from weak-motion aftershock recordings, to short- and midperiod amplification functions from previous studies (note that the Choi and Stewart (2005) functions have been evaluated at $\mathrm{PHA}_{r}=0.1 \mathrm{~g}$ ); (b) Comparison of amplification values computed in this study to (1) bias-adjusted average amplification factors referenced to $V_{s 30}=760 \mathrm{~m} / \mathrm{sec}$ by Choi and Stewart (2005), (2) NEHRP amplification factors (reference site $V_{s 30}=760 \mathrm{~m} / \mathrm{sec}$ ), (3) Borcherdt (2002) (reference site $V_{s 30} \approx 850 \mathrm{~m} / \mathrm{sec}$ ), (4) Stewart et al. (2003) factors bias adjusted to reference condition $V_{s 30}=760 \mathrm{~m} / \mathrm{sec}$, and (5) Joyner and Boore (2000) for reference condition of $V_{s 30}=760 \mathrm{~m} / \mathrm{sec}$. 
the profile-indicating the variability of site conditions categorized as class $\mathrm{C}$ based on the $V_{s 30}$ criterion and associated variability in amplification potential of the corresponding formations. Nonetheless, there exists no clear trend for the weak ground motions investigated herein as a function of the reference-site PGA, which implies that the amplification potential of these sites is not associated with nonlinear site-response for the entire spectrum of groundmotion level investigated. By contrast, however, amplification factors predicted for class D site conditions show a clear exponential decaying trend with reference-site groundmotion amplitude with data largely scattered both for the short and long period components between 0.5 and 5 in the low amplitude region $\left(\mathrm{PHA}_{r}>0.01 \mathrm{~g}\right)$ of ground motions.

The observed highly scattered amplitude dependency of amplification factors for the weak ground-motion levels investigated highlights the insufficiency of currently employed site classification criteria based on impedance averaging to describe consistently the amplification potential of soil profiles within the same site class, while it may here be interpreted as the initiation of nonlinear effects at a peak ground acceleration threshold lower than observed for site classes A-C. Even further, inasmuch as this study investigates the variation of short and long period site amplification factors as a function of $V_{s 30}$ in a subduction zone of interest (while published site amplification factors are derived from databases that may exclude subduction and interplate events), both the highly scattered nature of site amplification factors in the weak-motion range, and the strong-motion siteresponse analyses of the same region we are currently undertaking are opting to support the reevaluation and improvement of currently employed hazard analyses for the U.S. by advancing the understanding of representation of the physical mechanisms rather than verifying the existing attenuation relations amplification factors.

\section{Mainshock versus Aftershock: Traditional Site Amplification Spectra}

Finally, averaged site amplification spectra obtained from the 2003 Miyagi-Oki aftershock sequence observations for the ensemble of site conditions investigated, are here compared to the corresponding mainshock site amplification functions to illustrate the implications of nonlinear site response in the amplification potential of near-surface formations. By contrast to the weak-motion excitation, during which the near-surface material was anticipated to exhibit linear elastic response, the lack of information on the nonlinear material properties at the sites of interest did not allow estimates of the strong-motion site response to be made via deconvolution. Nonetheless, while estimates of rock-outcrop motion in this case would considerably increase the uncertainty associated with the nonlinear soil response to transient loading, the borehole mainshock records are here expected to be less contaminated by downgoing waves due to the in- creased material absorption in the near surface, thus improving the true site-amplification assessment capabilities of the corresponding surface-to-borehole site-response estimates.

In the ensuing, Figure 14a compares surface-to-borehole site-response spectra and cross-spectral ratios, and $\mathrm{H} / \mathrm{V}$ ground surface ratios of weak and mainshock recordings at the stations investigated, averaged across the sites within each of the three classes examined. Typical effects of nearsurface material nonlinearity, such as reduction in the resonant frequency of the formation resulting from the average reduced stiffness in the duration of seismic excitation, are manifested here, as can be seen by comparing the mainshock to the aftershock site-response estimates; counterintuitively, however, these effects are more pronounced in the highfrequency region $(10-20 \mathrm{~Hz})$ of class $\mathrm{B}$ and class $\mathrm{C}$ sites, indicating that the near-surface soft layers of these profiles are by average subjected to short-wavelength, highamplitude motion, and the resulting strain exerted by the material exceeds the linear elastic region. On the contrary, class D site conditions are shown, by average, to be unaltered in terms of amplification potential during the mainshock. Furthermore, the standard deviation of the strongly scattered distribution in the weak motion range is shown to be decreased by the introduction of nonlinear effects and associated site-dependent variability in the altering of material properties.

Examples that corroborate the observation made previously are shown in Figure 14b. Profiles MYGH04 and IWTH23, classified as class B conditions according to the weighted average near-surface shear-wave velocity criterion, are characterized by near-surficial very soft sedimentary deposits overlying considerably stiffer formations at strong impedance contrast; as a result, high-frequency components corresponding to wavelengths on the same order of magnitude as the thickness of these layers are trapped in the near surface and subject the material to strains beyond the elastic region, causing the amplification signature of the profiles to shift in the lower-frequency region. On the contrary, sites IWTH20 and ITHW15, classified as class D sites, only show a slight reduction in the amplitude of high-frequency components, while the incident mainshock wavelengths of comparable length to the near-surface nonlinearity-susceptible material are shown not to carry energy adequate to strain the material in the nonlinear range.

\section{Discussion and Conclusions}

In this study, geotechnical array recordings at 38 stations of the Japanese strong-motion network KiK-Net from the $2003 M_{\mathrm{w}} 7.0$ Miyagi-Oki aftershock sequence were used for the development of velocity-attenuation relations, the comparison of single-station and reference-station site amplification estimates, and the estimation of site amplification factors for three classes of site conditions (B, C, and D), while the weak-motion site amplification ratios were also compared to the mainshock site-response observations. 

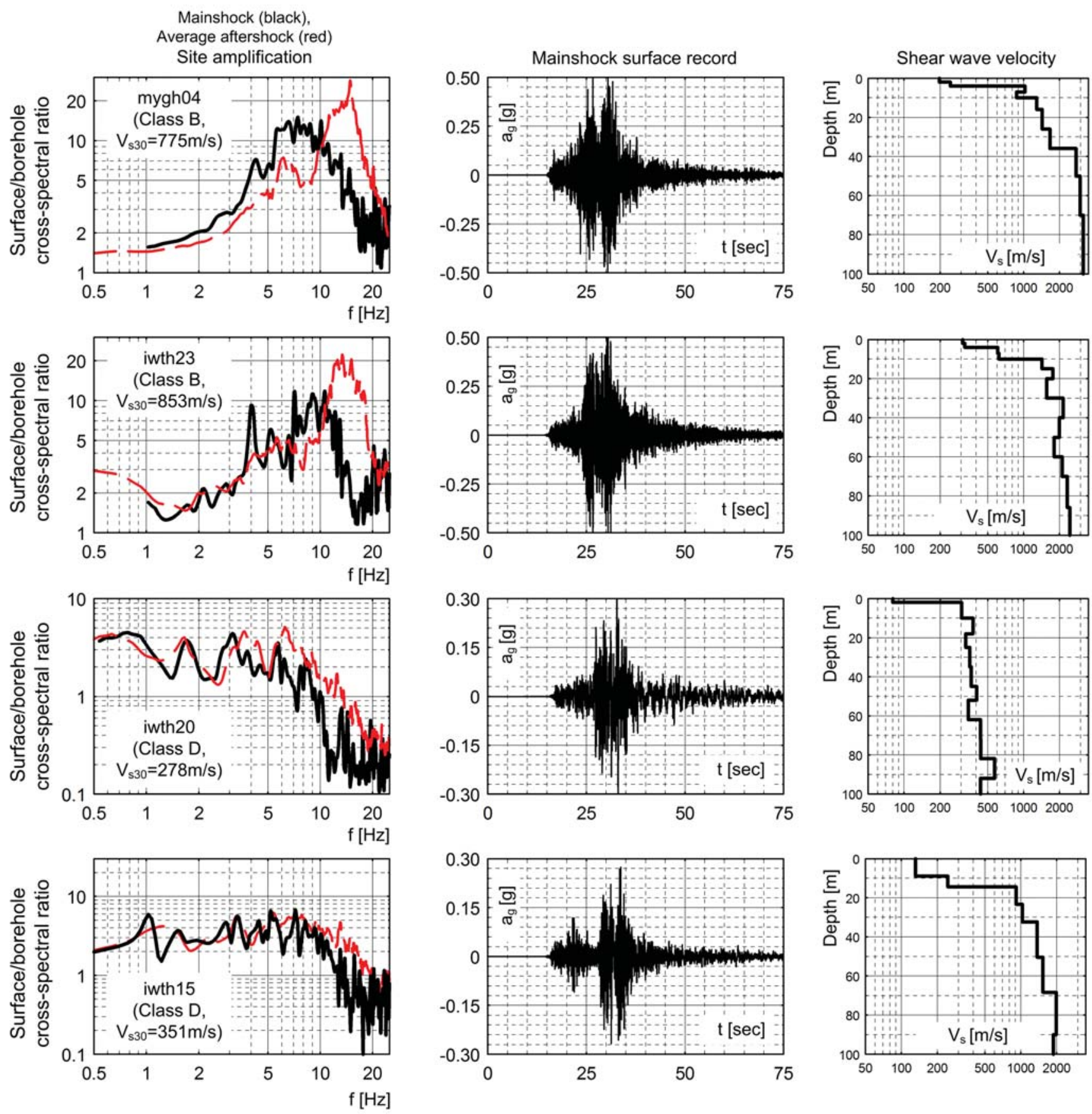

Figure 14. (a) Comparison of surface-to-borehole site-response spectra, cross-spectral ratios, and H/V ground surface ratios of weak and mainshock recordings at the stations investigated, averaged across the sites within each of the three classes examined (black solid line, average mainshock; red solid line, aftershock recordings). (b) Comparison of average aftershock and mainshock surface-to-borehole site response at selected stations (left), mainshock surface-ground-motion records, and associated shear-wave velocity profiles as estimated by means of downhole array seismogram inversion.

Initially, a hybrid stochastic-deterministic seismic waveform inversion algorithm was implemented for the evaluation high-resolution, low-strain velocity $\left(V_{s}\right)$, attenuation $\left(Q_{s}\right)$, and density profiles at the sites of interest. Based on the inversion results, $V_{s}-Q_{s}$ correlations are derived for the region of interest, and the observed highly erratic behavior of the developed relationships was attributed to the multitude of physical attenuation mechanisms represented by means of a simplified forward wave-propagation model. Results obtained in this study and corroborated by past published correlations suggest that $V_{s}-Q_{s}$ relations obtained by means of simplified models simulating the complex multitude physical mechanisms of energy absorption and redistribution in the upper few hundreds of meters of the crust may not be em- 
ployed to extrapolate attenuation profiles in adjacent sites due to the highly heterogeneous nature of soil materials at these depths.

Next, surface-to-downhole traditional (SSR) and crossspectral (cSSR) ratios and H/V site-response estimates were compared, and their effectiveness was evaluated as a function of the site class investigated, evaluated on the basis of the inverted shear-wave velocity profiles. The single and reference-station site-response estimates were also compared to surface-to-rock-outcrop spectral ratios, evaluated by deconvolution of the downhole recorded motions to the rock outcrop. Destructive interference phenomena were shown to result in systematic overestimation of the site response by means of the surface-to-borehole transfer function, with the exception of the single-station $\mathrm{H} / \mathrm{V}$ site-amplification estimates in the low-frequency range, with the observed crossspectral surface-to-borehole to approximate satisfactorily the estimated surface-to-rock-outcrop amplification. Discrepancies between the average traditional surface-to-borehole observed and surface-to-rock-outcrop amplification were found to be less prominent as the near-surface stiffness of the profile decreases, stemming directly from the increased impedance contrast between the near surface and underlying stiffer layers that prevents destructive interference phenomena at the borehole level. While this trend was observed for the averaged spectra of site amplification, however, examples were illustrated where the site-specific conditions and associated site classification do not reflect the anticipated amplification potential of the corresponding site class.

Successively, site amplification factors were derived from weak-motion recordings, using the seismogram inversion results at the geotechnical arrays of interest and deconvolving the downhole and surface observations to a typical NEHRP B-C boundary reference-site-surface ground motion. Both short- and long-period amplification factors are shown to be consistent with previous studies for class B site conditions, while amplification factors were found to be substantially more scattered for class $\mathrm{C}$ and $\mathrm{D}$ conditionsespecially in the short-period region reflecting amplification of short wavelengths trapped in the near-surficial layers of the profile-indicating the variability of profiles homogeneously classified based on the $V_{s 30}$ criterion and associated variability in amplification potential of the corresponding formations. In particular, for the amplification factors predicted for class $\mathrm{D}$ site conditions, a clear exponential decaying trend with reference-site ground-motion amplitude was revealed, potentially attributed to the initiation of nonlinear effects at a peak-ground-acceleration threshold lower than observed for site classes B and C.

Finally, surface-to-borehole site-response spectra and cross-spectral ratios, and $\mathrm{H} / \mathrm{V}$ ground-surface ratios of weak and mainshock recordings were compared and averaged within each of the three classes examined. Counterintuitively, typical effects of near-surface material nonlinearity - such as reduction in the resonant frequency of the formation-were shown to manifest in the high- frequency region (10-20 Hz) of class B and class C sites, indicating that the near-surface soft layers of these profiles were by average subjected to short-wavelength, high amplitude motion, and the resulting strain exerted by the material exceeded the linear elastic region. On the contrary, class D sites were shown by average to be unaltered in terms of amplification potential during the mainshock.

Overall, results presented in this study highlight the need for site classification criteria to be reevaluated and refined accordingly, opting to reflect more realistically the anticipated average response of near-surface formations. In particular, the observations of this work suggest that for a complete description of the site amplification potential (and associated nonlinearity susceptibility under strong ground motion), the existing near-surface averaged impedance categorization of soil profiles should be complemented by a quantitative description of the similarities between incident-motion frequency content and theoretical site amplification, thus illustrating the potential of the local site conditions to amplify (or deamplify) the incoming seismic energy. Toward the establishment of a framework for site-specific ground response analysis as a function of site conditions, incident motion characteristics and a design sophistication level that will account for site effects in the current state of practice based on physical fundamental principles rather than phenomenological, site-specific approximations associated with a cost-effective site investigation programs based on blind predictions and sensitivity analyses, downhole array recordings should be used more extensively toward the understanding and modeling of complex site-response phenomena.

\section{Data Sources}

Seismograms used in this study were collected by instruments of the Japanese strong-motion network KiK-Net, which is operated by NIED as part of the activities of the headquarters for earthquake research promotion. Seismic records and geophysical investigation results at the locations of the network's stations can be obtained at the KiK-Net web site http://www.kik.bosai.go.jp/ (last accessed February 2007).

\section{Acknowledgments}

The authors would like to acknowledge the two reviewers of this manuscript, Bruno Hernandez and Seiji Tsuno, whose valuable comments contributed to improvements of the context and presentation of our work.

\section{References}

Abercrombie, R. (1997). Near-surface attenuation and site effects from comparison of surface and deep borehole recordings, Bull. Seismol. Soc. Am. 87, 731-744.

Abrahamson, N. A., and W. J. Silva (1997). Empirical response spectral attenuation relations for shallow crustal earthquakes, Seism. Res. Lett. 68, 94-127. 
Aguirre, J., and K. Irikura (1997). Nonlinearity, liquefaction, and velocity variation of soft soil layers in Port Island, Kobe, during the Hyogoken Nanbu earthquake, Bull. Seismol. Soc. Am. 87, 1244-1258.

Annaka, T., and Y. Nozawa (1988). A probabilistic model for seismic hazard estimation in the Kanto district, in Proc. 9th World Conf. Earthquake Eng., Vol. 2, 107-112.

Aoi, S., K. Obara, S. Hori, K. Kasahara, and Y. Okada (2000). New Japanese uphole-downhole strong-notion observation network: KiK-Net, Seism. Res. Lett. 72, 239.

Arai, H., and K. Tokimatsu (2000). Effects of Rayleigh and Love waves on microtremor H/V spectra (Article 2232), in Proc. 12th World Conf. Earthquake Eng., Auckland, New Zealand, 30 January-4 February 2000 (available on CD-ROM).

Archuleta, R. J., S. H. Seale, P. V. Sangas, L. M. Baker, and S. T. Swain (1992). Garner Valley downhole array of accelerometers: instrumentation and preliminary data analysis, Bull. Seismol. Soc. Am. 82, 1592-1621.

Archuleta, R. J., S. H. Seale, P. V. Sangas, L. M. Baker, and S. T. Swain (1993). Garner Valley downhole array of accelerometers: instrumentation and preliminary data analysis, Bull. Seismol. Soc. Am. 83, no. 6, 2039.

Assimaki, D., and J. H. Steidl (2007). Inverse analysis of weak and strong motion downhole array data from the $M_{\mathrm{w}} 7.0$ Sanriku-Minami earthquake, Soil Dyn. Earthq. Eng. 27, no. 1, 73-92.

Assimaki, D., J. H. Steidl, and P. C. Liu (2006). Attenuation and velocity structure for site response analyses via downhole seismogram inversion, Pure Appl. Geophys. 163, no. 1, 81-118.

Bendat, J. S., and A. G. Piersol (1980). Engineering Applications of Correlation and Spectral Analyses, Wiley, New York, 302 pp.

Bersini, H., and B. Renders (1994). Hybridizing genetic algorithms with hill-climbing methods for global optimization: two possible ways, in Proc. IEEE International Symposium Evolutionary Computation, Orlando, Florida.

Boatwright, J., J. B. Fletcher, and T. E. Fumal (1991). A general inversion scheme for source, site, and propagation characteristics using multiply recorded sets of moderate-sized earthquakes, Bull. Seismol. Soc. Am. 81, 1754-1782.

Boatwright, J., L. C. Seekins, and C. S. Mueller (1991). Ground motion amplification in the marina, Bull. Seismol. Soc. Am. 81, 1980-1997.

Bonilla, L. F., J. H. Steidl, G. T. Lindley, A. G. Tumarkin, and R. J. Archuleta (1997). Site amplification in the San Fernando Valley, California: variability of site-effect estimation using the $S$-wave, coda, and H/V methods, Bull. Seismol. Soc. Am. 87, 710-730.

Boore, D. M., and W. B. Joyner (1997). Site amplification for generic rock sites, Bull. Seismol. Soc. Am. 87, 327-341.

Borcherdt, R. D. (1970). Effects of local geology on ground motion near San Francisco Bay, Bull. Seismol. Soc. Am. 60, 29-61.

Borcherdt, R. D. (1994). Estimates of site-dependent response spectra for design (methodology and justification), Earthq. Spectra 10, no. 4, 617-653.

Borcherdt, R. D. (2002). Empirical evidence for acceleration-dependent amplification factors, Bull. Seismol. Soc. Am. 92, 761-782.

Borcherdt, R. D., and J. F. Gibbs (1976). Effects of local geological conditions in the San Francisco Bay region on ground motions and the intensities of the 1906 earthquake, Bull. Seismol. Soc. Am. 66, 467-500.

Borcherdt, R. D., and G. Glassmoyer (1994). Influences of local geology on strong and weak ground motions recorded in the San Francisco Bay region and their implications for site-specific building-code provisions - the Loma Prieta, California, earthquake of October 17, 1989-strong ground motion, U.S. Geol. Surv. Profess. Pap. 1551-A, A77-A108.

Brown, L. T., D. M. Boore, and K. H. Stokoe II (2002). Comparison of shear-wave slowness profiles at 10 strong-motion sites from noninvasive SASW measurements and measurements made in boreholes, Bull. Seismol. Soc. Am. 92, no. 8, 3116-3133.

Building Seismic Safety Council (BSSC) (2001). FEMA-368 and FEMA 369: NEHRP recommended provisions for seismic regulations for new buildings and other structures, Part 1: Provisions and Part 2: Commentary, Federal Emergency Management Agency, Washington, D.C.

Campbell, K. W., and Y. Bozorgnia (2003). Updated near-source ground motion (attenuation) relations for the horizontal and vertical components of peak ground acceleration and acceleration response spectra, Bull. Seismol. Soc. Am. 93, 314-331.

Causse, E., R. Mittet, and B. Ursin (1999). Preconditioning of full waveform inversion in visco-acoustic media, Geophysics 64, no. 1, 130-145.

Chaderjian, B. J. (1994). A uniqueness theorem for a lossy inverse problem in reflection seismology, SIAM J. Appl. Math. 54, 1224-1249.

Chin, B., and K. Aki (1991). Simultaneous study of the source, path, and site effects on strong ground motion during the 1989 Loma Prieta earthquake: a preliminary result on pervasive nonlinear site effects, Bull. Seismol. Soc. Am. 81, 1859-1884.

Choi, Y., and J. P. Stewart (2005). Nonlinear site amplification as function of 30-m shear wave velocity, Earthq. Spec. 21, no. 1, 1-30.

Dobry, R., R. D. Borcherdt, C. B. Crouse, I. M. Idriss, W. B. Joyner, G. R. Martin, M. S. Power, E. E. Rinne, and R. B. Seed (2000). New site coefficients and site classification system used in recent building seismic code provisions, Earthq. Spec. 16, no. 1, 41-67.

Douglas, J. (2003). Earthquake ground motion estimation using strongmotion records: a review of equations for the estimation of peak ground acceleration and response spectral ordinates, Earth Sci. Rev. 61, no. 1, 43-104.

Field, E. H. (1996). Spectral amplification in a sediment-filled valley exhibiting clear basin-edge induced waves, Bull. Seismol. Soc. Am. 86, 991-1005.

Field, E. H. (2000). A modified ground motion attenuation relationship for southern California that accounts for detailed site classification and a basin depth effect, Bull. Seismol. Soc. Am. 90, S209-S221.

Field, E. H., and K. H. Jacob (1995). A comparison and test of various site response estimation techniques, including three that are non referencesite dependent, Bull. Seismol. Soc. Am. 85, 1127-1143.

Field, E. H., P. A. Johnson, I. A. Beresnev, and Y. Zeng (1997). Nonlinear ground-motion amplification by sediments during the 1994 Northridge earthquake, Nature 390, 599-602.

Foti, S., and C. G. Lai (1999). Determinazione delle proprieta dinamiche dei terreni mediante l'uso di onde superficiali, in Atti XX Convegno Nazionale di Geotecnica, Patron Editore, Bologna, Italy (in Italian).

Frankel, A. D., C. S. Mueller, T. P. Barnhard, E. V. Leyendecker, R. L. Wesson, S. C. Harmsen, F. W. Klein, D. M. Perkins, N. C. Dickman, S. L. Hanson, and Hopper (2000). USGS national seismic hazard maps, Earthq. Spectra 16, 1-20.

Gibbs, J., and E. Roth (1989). Seismic velocities and attenuation from borehole measurements near the Parkfield prediction zone, central California, Earthq. Spectra 5, 513-537.

Gibbs, J., D. Boore, W. Joyner, and T. Fumal (1994). The attenuation of seismic shear waves in quaternary alluvium in Santa Clara valley, California, Bull. Seismol. Soc. Am. 84, 76-90.

Guzina, B. B., and A. Lu (2002). Coupled waveform analysis in dynamic characterization of lossy solids, J. Eng. Mech. Div. ASCE, 128, no. 4.

Harmsen, S. C. (1997). Determination of site amplification in the Los Angeles urban area from inversion of strong-motion records, Bull. Seismol. Soc. Am. 87, 866-887.

Hartzell, S. H. (1992). Site response estimation from earthquake data, Bull. Seismol. Soc. Am. 82, 2308-2327.

Hartzell, S. H., A. Leeds, A. Frankel, and J. Michael (1996). Site response for urban Los Angeles using aftershocks of the Northridge earthquake, Bull. Seismol. Soc. Am. 86, S168-S192.

Hartzell, S. H., S. A. Leeds, A. Frankel, R. A. Williams, J. Odum, W. Stephenson, and W. Silva (2002). Simulation of broadband ground motion including nonlinear soil effects for a magnitude 6.5 earthquake on the Seattle fault, Seattle, Washington, Bull. Seismol. Soc. Am. 92, 831-853.

Horike, M. (1993). Studies on microtremors, J. Seism.Soc. Jpn. Ser. 2, 46, 343-350 (in Japanese with English abstract). 
Houck, C. R., J. I. Joines, and M. G. Kay (1996). Comparison of genetic algorithms, random restart and two-opt switching for solving large location-allocation problems, Comp. Oper. Res. 23, 587-596.

Iai, S., T. Morita, T. Kameoka, Y. Matsunaga, and K. Abiko (1995). Response of a dense sand deposit during 1993 Kushiro-Oki earthquake, Soils Found. 35, 115-131.

Joyner, W. B., and D. M. Boore (2000). Recent developments in earthquake ground motion estimation, in Proc. 6th International Conf. on Seismic Zonation, Palm Springs, California, 12-15 November 2000.

Joyner, W. B., T. E. Fumal, and G. Glassmoyer (1994). Empirical response spectral ratios for strong motion data from the 1989 Loma Prieta, California, earthquake, in Proc. of the 1992 NCEER/SEAOC/BSSC Workshop on Site Response during Earthquakes and Seismic Code Provisions, G. R. Martin (Editor), University of Southern California, National Center for Earthquake Engineering Research Spec. Publ. NCEER-94-SP01, Buffalo, New York.

Kailath, T. (1981). Lectures on Wiener and Kalman Filtering, Springer, New York.

Kato, K., K. Aki, and M. Takemura (1995). Site amplification from coda waves: validation and application to $S$-wave site response, Bull. Seismol. Soc. Am. 85, 467-477.

Kawanoa, M., K. Asanob, H. Dohi, and S. Matsuda (2000). Verification of predicted nonlinear site response during the 1995 Hyogo-Ken Nanbu earthquake, Soil Dyn. Earthq. Eng. 20, nos. 5-8, 493-507.

Kinoshita, S. (1998). Kyoshin net (K-Net), Seism. Res. Lett. 69, 309-332.

Kramer, S. L., and S. B. Paulsen (2004). Practical use of geotechnical site response models, in Proc. Int. Workshop on Uncertainties in Nonlinear Soil Properties and their Impact on Modeling Dynamic Soil Response, University of California, Berkeley, $10 \mathrm{pp}$.

Kudo, K., and E. Shima (1970). Attenuation of shear waves in soil, Bull. Earthquake Res. Inst. 48, 145-148.

Kudo, K., Y. Sawada, and M. Horike (2004). Current studies in Japan on $H / V$ and phase velocity dispersion of microtremors for site characterization, in Proc. 13th World Conference on Earthquake Engineering, Paper No. 1144.

Lachet, C., and P. Y. Bard (1994). Numerical and theoretical investigations on the possibilities and limitations of Nakamura's technique, J. Phys. Earth 42, 377-397.

Lachet, C., D. Hatzfeld, P.-Y. Bard, N. Theodulidis, C. Papaioannou, and A. Savvaidis (1996). Site effects and microzonation in the city of Thessaloniki (Greece) comparison of different approaches, Bull. Seismol. Soc. Am. 86, no. 6, 1692-1703.

Lai, C. G. (1998). Simultaneous inversion of Rayleigh phase velocity and attenuation for near-surface site characterization, Ph.D. Thesis, Georgia Institute of Technology, Atlanta, Georgia.

Lermo, J., and F. J. Chávez-García (1993). Site effect evaluation using spectral ratios with only one station, Bull. Seismol. Soc. Am. 83, no. 5, 1574-1594.

Lu, L., F. Yamazaki, and T. Katayama (1992). Soil amplification based on seismometer array and microtremor observations in Chiba, Japan, Earthquake Eng. Struct. Dyn. 21, 95-108.

Luco, J. E., and H. L. Wong (1986). Response of a rigid foundation to a spatially random ground motion, Earthquake Eng. Struct. Dyn. 14, 891-908.

Margheriti, L., L. Wennerberg, and J. Boatwright (1994). A comparison of coda and $S$-wave spectral ratios as estimates of site response in the southern San Francisco Bay area, Bull. Seismol. Soc. Am. 84, no. $6,1815-1830$.

Martinez, R. D., and G. A. McMechan (1991). $\tau$-p seismic data for viscoelastic media, part 2: linearized inversion, Geophys. Prospect. 39, no. $2,157-181$.

Matsushima, T., and H. Okada (1990a). Determination of deep geological structures under urban areas, J. Soc. Explor. Geophys. Jpn. 43, no. 1, 21-33.

Matsushima, T., and H. Okada (1990b). An exploration method using microtremors (2), an experiment to identify Love waves in long-period microtremors, in Proc. 82nd Annual Spring Meeting, Soc. Exploration Geophys. Japan, Tsukuba, 23-25 May 1990, 5-8 (in Japanese).

Morikawa, N., and T. Sasatani (2003). Source spectral characteristics of two large intra-slab earthquakes along the southern Kurile-Hokkaido arc, Phys. Earth Planet. Interiors 137, no. 1, 67-80.

O'Neill, A. (2003). Full-waveform reflectivity for modeling, inversion and appraisal of seismic surface wave dispersion in shallow site investigations, M.Sc. Thesis, The University of Western Australia: available at: www.geol.uwa.edu.au/ aoneill/, (last accessed February 2007).

Parolai, S., and S. Richwalski (2004). The importance of converted waves in comparing H/V and RSM site response estimates, Bull. Seismol. Soc. Am. 94, no. 1, 304-313.

Phillips, W. S., and K. Aki (1986). Site amplification of coda waves from local earthquakes in Central California, Bull. Seismol. Soc. Am. 76, 627-648.

Pujol, J., S. Pezeshk, Y. Zhang, and C. Zhao (2002). Unexpected Values of $Q_{s}$ in the unconsolidated sediments of the Mississippi embayment, Bull. Seismol. Soc. Am. 92, no. 3, 1117-1128.

Riepl, J., P.-Y. Bard, D. Hatzfeld, C. Papaioannou, and S. Nechtschein (1998). Detailed evaluation of site-response estimation methods across and along the sedimentary valley of Volvi (EURO-SEISTEST), Bull. Seismol. Soc. Am. 88, no. 2, 488-502.

Rix, G., C. Lai, and A. Spang (2000). In situ measurement of damping ratio using surface waves, J. Geotech. Geoenviron. Eng. 126, no. 5, 472-480.

Sadigh, K., C.-Y. Chang, J. A. Egan, F. Makdisi, and R. R. Youngs (1997). Attenuation relations for shallow crustal earthquakes based on California strong motion data, Seism. Res. Lett. 68, 180-189.

Safak, E. (1997). Models and methods to characterize site amplification from a pair of records, Earthq. Spectra 13, no. 1, 97-129.

Sato, K., T. Kokusho, M. Matsumoto, and E. Yamada (1996). Nonlinear seismic response and soil property during strong motion, in Soils Found., Special Issue on the Geotechnical Aspects of the January 17, 1995, Hyogoken-Nanbu Earthquake, 41-52.

Satoh, T. (2004). Study on causes of large peak accelerations of the 2003 Miyagi-Oki earthquake based on strong ground motion records, J. Struct. Constr. Eng. 581, 31-38 (Japanese with English abstract).

Satoh, T., M. Fushimi, and Y. Tatsumi (2001). Inversion of strain-dependent nonlinear characteristics of soils using weak and strong motions observed by boreholes sites in Japan, Bull. Seismol. Soc. Am. 91, 365-380.

Satoh, T., T. Sato, and H. Kawase (1995). Nonlinear behavior of soil sediments identified by using borehole records observed at the Ashigar Valley, Japan, Bull. Seismol. Soc. Am. 85, no. 6, 1821-1834.

Scherbaum, F., K. G. Hinzen, and M. Ohrnberger (2003). Determination of shallow shear wave velocity profiles in the Cologne, Germany area using ambient vibrations, Geophys. J. Int. 152, 597-612.

Seed, H. B., and I. M. Idriss (1970). UCB/EERC-70/10: Soil moduli and damping factors for dynamic response analyses, Earthquake Engineering Research Center, University of California at Berkeley.

Shearer, P. M., and J. A. Orcutt (1987). Surface and near-surface effects on seismic waves: theory and borehole seismometer results, Bull. Seismol. Soc. Am. 77, 1168-1196.

Shi, H., and S. Midorikawa (1999). New attenuation relationships for peak ground acceleration and velocity considering effects of fault type and site condition, J. Struct. Constr. Eng. 523, 63-70 (in Japanese with English abstract).

Silva, W. J., N. A. Abrahamson, G. Toro, and C. Costantino (1997). Description and validation of the stochastic ground motion model, report to Brookhaven National Laboratory, Associated Universities, Inc., Upton, New York.

Steidl, J. H. (1993). Variation of site response at the UCSB dense array of portable accelerometers, Earthq. Spectra 9, 289-302.

Steidl, J. H. (2000). Site response in southern California for probabilistic seismic hazard analysis, Bull. Seismol. Soc. Am. 90, S149-S169. 
Steidl, J. H., A. G. Tumarkin, and R. J. Archuleta (1996). What is a reference site?, Bull. Seismol. Soc. Am. 86, 1733-1748.

Stewart, J. P., A. H. Liu, and Y. Choi (2003). Amplification factors for spectral acceleration in tectonically active regions, Bull. Seismol. Soc. Am. 93, 332-352.

Stoffa, P. L., and M. K. Sen (1991). Nonlinear multi-parameter inversion using genetic algorithms: inversion of plane-wave seismograms, Geophysics 56, 1794-1810.

Stubbs, N., V. S. Torpunuri, R. L. Lytton, and A. H. Magnuson (1994). A methodology to identify material properties in pavements modeled as layered viscoelastic halfspaces theory, ASTM Spec. Tech. Publ. 1198, 53-67.

$\mathrm{Su}, \mathrm{F}$., and K. Aki (1990). Temporal and spation variation of coda $Q_{s}$ associated with the North Palm Springs earthquake of July 8, 1986, Pure Appl. Geophys. 133, 23-52.

Su, F., J. G. Anderson, J. N. Brune, and Y. Zeng (1996). A comparison of direct $S$-wave and coda wave site amplification determined from aftershocks of Little Skull Mountain earthquake, Bull. Seismol. Soc. Am. 86, 1006-1018.

Tokimatsu, K. (1997). Geotechnical site characterization using surface waves, in Proc. IS-Tokyo '95/1st Int. Conf. Earthquake Geotechnical Eng., Tokyo, Japan, 14-16 November 1997, 1333-1368.

Tokimatsu, K., S. Wakai, and H. Arai (1998). Three-dimensional soil stratification using surface waves in microtremors, in Proc. 1st Int. Conf. Site Characterization (ISC'98), Atlanta, Georgia, 19-22 April 1998, 537-542.

Tsuda, K., J. Steidl, R. Archuleta, and D. Assimaki (2006). Site-response estimation for the 2003 Miyagi-Oki earthquake sequence considering nonlinear site response, Bull. Seismol. Soc. Am. 96, no. 4A, 1474-1482.

Uzan, J. (1994). Advanced backcalculation techniques, Am. Soc. Test. Mat. Spec. Tech. Publ. 1198, 3-37.
Wald, L., and J. Mori (2000). Evaluation of methods for estimating linear site-response magnification in the Los Angeles region, Bull. Seismol. Soc. Am. 90, S32-S42.

Welch, P. D. (1967). The use of fast fourier transform for the estimation of power spectra: a method based on time averaging over short, modified periodograms, IEEE Trans. Audio Electroacoust. AU-15, 70-73.

Wen, K., I. Beresnev, and Y. T. Yeh (1994). Nonlinear soil amplification inferred from downhole strong seismic motion data, Geophys. Res. Lett. 21, 2625-2628.

Yamanaka, K., and M. Kikuchi (2003). Source processes of the Tokachi-Oki earthquake on September 26, 2003, inferred from teleseismic body waves, Earth Planet Space 55, 21-24.

Zeghal, M., and A. W. Elgamal (1994). Analysis of site liquefaction using earthquake records, J. Geotech. Eng. ASCE, 120, no. 6, 996-1017.

Georgia Institute of Technology

School of Civil and Environmental Engineering

790 Atlantic Drive NW

Atlanta, Georgia 30332

dominic.assimaki@ce.gatech.edu

wli3@mail.gatech.edu

(D.A., W.L.)

Institute for Crustal Studies

University of California

Santa Barbara, California 93106

steidl@crustal.ucsb.edu

kenichi@crustal.ucsb.edu

(J.H.S., K.T.)

Manuscript received 13 January 2007 